\title{
WestVirginiaUniversity
}

THE RESEARCH REPOSITORY @ WVU

Graduate Theses, Dissertations, and Problem Reports

2009

\section{Variation in, and contributing factors of placental efficiency in swine}

Tiffany Ann Wilmoth

West Virginia University

Follow this and additional works at: https://researchrepository.wvu.edu/etd

\section{Recommended Citation}

Wilmoth, Tiffany Ann, "Variation in, and contributing factors of placental efficiency in swine" (2009). Graduate Theses, Dissertations, and Problem Reports. 2811.

https://researchrepository.wvu.edu/etd/2811

This Thesis is protected by copyright and/or related rights. It has been brought to you by the The Research Repository @ WVU with permission from the rights-holder(s). You are free to use this Thesis in any way that is permitted by the copyright and related rights legislation that applies to your use. For other uses you must obtain permission from the rights-holder(s) directly, unless additional rights are indicated by a Creative Commons license in the record and/ or on the work itself. This Thesis has been accepted for inclusion in WVU Graduate Theses, Dissertations, and Problem Reports collection by an authorized administrator of The Research Repository @ WVU. For more information, please contact researchrepository@mail.wvu.edu. 
Variation in, and Contributing Factors of Placental Efficiency in Swine

Tiffany Ann Wilmoth

Thesis submitted to the Davis College of Agriculture, Forestry and Consumer Sciences at West Virginia University in partial fulfillment of the requirements for the degree of

Master of Science

in

Reproductive Physiology

Matthew E. Wilson, Ph.D., Chair

Kenneth P. Blemings, Ph.D.

Kimberly M. Barnes, Ph.D.

Division of Animal and Nutritional Sciences

Morgantown, WV

2009

Keywords: Placental Efficiency, Nutrient Transport, Vascular Density, Swine 


\section{ABSTRACT \\ Variation in and Contributing Factors of Placental Efficiency in Swine}

\section{Tiffany Ann Wilmoth}

Placental efficiency, defined as fetal weight divided by placental weight, has been shown to be involved in litter size. Breeds that are more prolific (12-13 pigs per litter) have feto-placental units with higher placental efficiencies. However, domestic commercial breeds have much smaller litters of about 9.5 pigs per litter. Placental size is vastly different, such that high placental efficiency pigs have smaller, more vascularized placentae. Even within an individual litter two piglets with similar body weights may be grown on placentae that are different in size. The placenta of the least efficient feto-placental unit may be up to $50 \%$ bigger than the placenta of the most efficient feto-placental unit. The fetus relies on the placenta for the transport of nutrients from the dam to the fetus. Both the size of the placenta, and the amount of vasculature of the placenta and endometrium, are important for the transport of nutrients to the fetus. Therefore, the objectives of the current experiment were to determine the mRNA expression of nutrient transporters in both the placenta and endometrium and to see if a relationship existed between placental efficiency and the expression of nutrient transporters and vascular density. Gilts were bred by artificial insemination 12 and 24 hours following the detection of estrus and at this time were randomly assigned to be ovario-hysterectomized on days 70,90 or 110 of gestation. At the time of ovario-hysterectomy, placental and endometrial samples were collected for the determination of nutrient transporter expression and vascular density. Other fetal characteristics were recorded, such as fetal weight, placental weight, and placental efficiency. Placental efficiency and the range of placental efficiency increased as gestation proceeded to day 90 and 110, with a near threeand four-fold increase, respectively. Fetal and placental weights were positively correlated throughout gestation. Placental weights were negatively correlated with placental efficiency throughout the final third of gestation. The vascular densities of the placenta and endometrium were positively correlated for days 70, 90 and 110 of gestation. Late in gestation, placental vascular density had negative relationships with both placental and fetal weights. However, no relationship was observed between placental efficiency and vascular density. Also, no relationships were detected between placental efficiency and the mRNA expression of nutrient transporters. There were also no interactions observed between expression of nutrient transporters and day of gestation. Day of gestation, however, was found to be an important influence on placental efficiency. Placental vascularity has been shown to influence placental efficiency in the past, though it did not here, there have also been instances where placental vascular density was not affected by selection for increased placental efficiency. The RNA message for the protein transporter may not be an effective way to estimate actual transport of nutrients or the types of nutrients being transported. 


\section{TABLE OF CONTENTS}

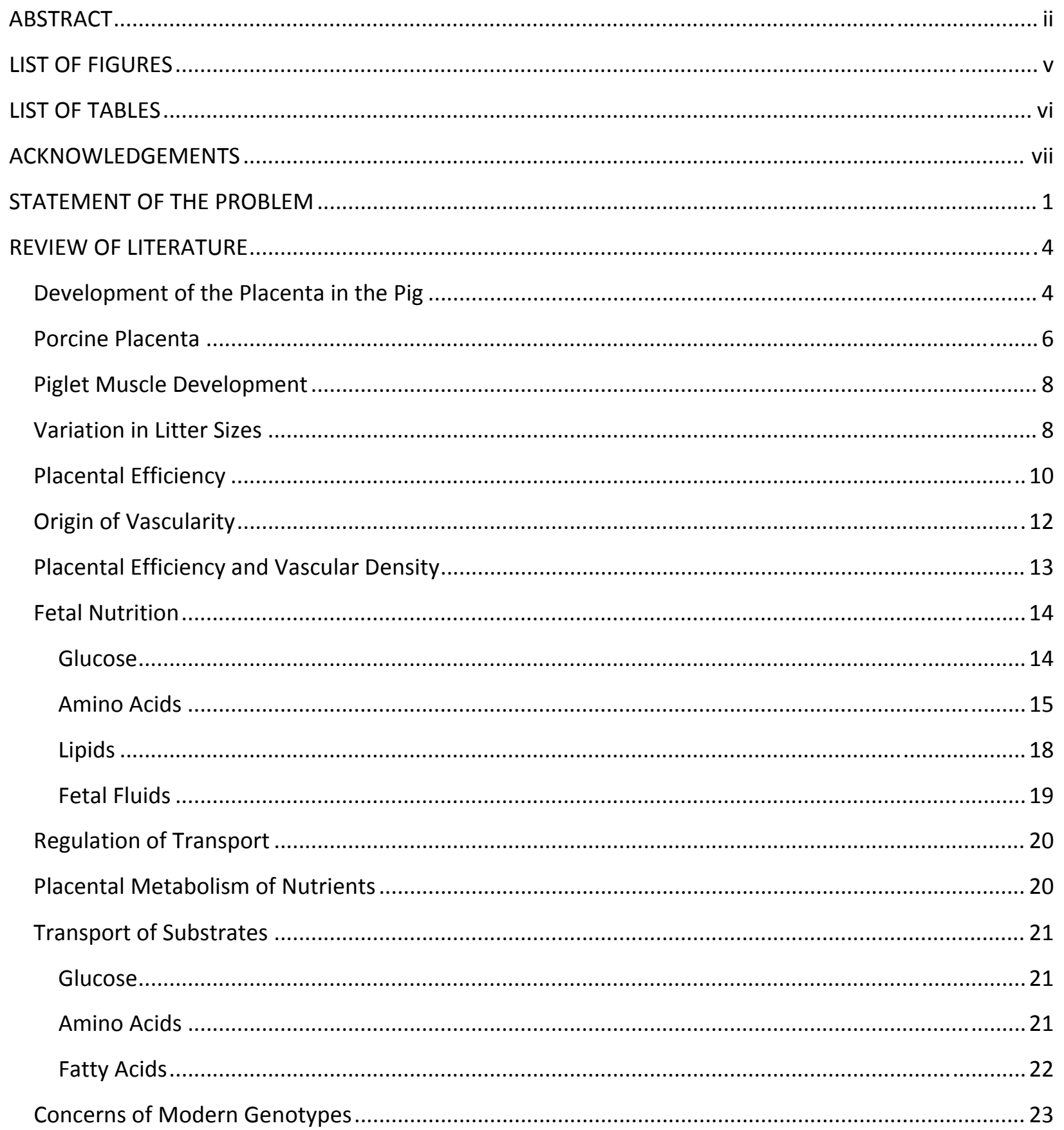

FACTORS CONTRIBUTING TO THE VARIATION IN PLACENTAL EFFICIENCY ON DAYS 70, 90 AND 110 OF

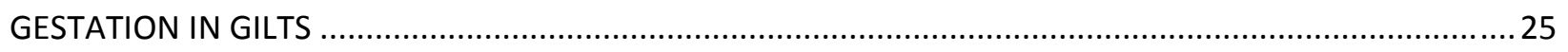

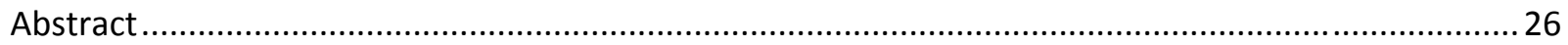

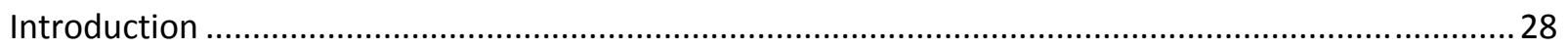

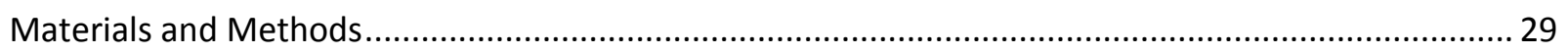




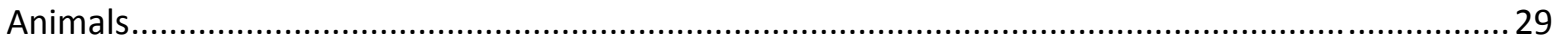

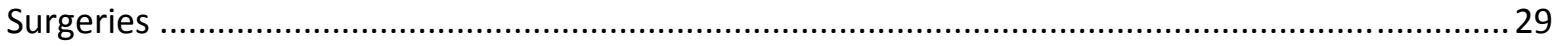

Determination of the mRNA Expression of Nutrient Transporters .................................................. 30

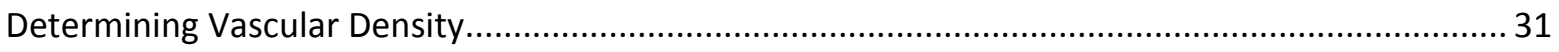

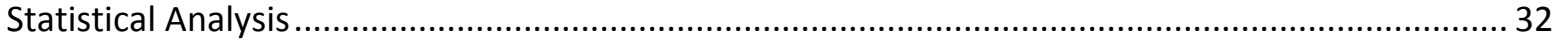

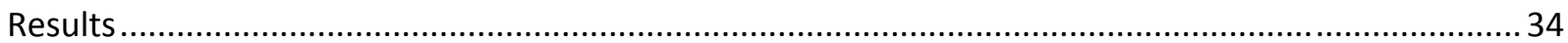

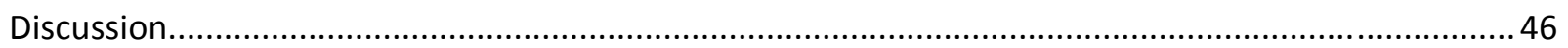

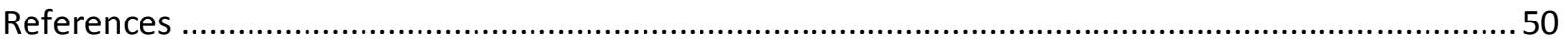

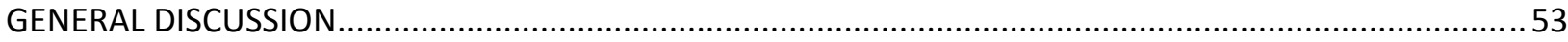

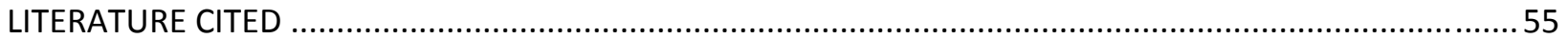




\section{LIST OF FIGURES}

Figure 1: Mean placental efficiency values from litters of pigs on days 70, 90 and 110 of gestation.

*indicates a difference in placental efficiency on that day of gestation $(P<0.0001)$.....

Figure 2: Range of values for placental efficiency for individual litters on day 70, 90 and 110 of gestation. represents litters on day $70, \boldsymbol{a}$ represents litters on day 90 and $\boldsymbol{\Delta}$ represents litters on day 110

Figure 3: Correlations between placental weight and fetal weight for days 70 (3A), 90 (3B) and 110 (3C) of gestation. Positive relationships were exhibited for each day and were increasingly stronger throughout gestation

Figure 4: Relationships between placental efficiency and placental weight for days 70 (4A), 90 (4B) and $110(4 \mathrm{C})$. Negative correlations existed for all days and were reduced as gestation proceeded

Figure 5: Mean liver weights for litters on day 70, 90 and 110 of gestation. ${ }^{*}$ indicate differences between day of gestation

Figure 6: Mean heart weights for litters on days 70, 90 and 110 of gestation. ${ }^{*}$ indicates differences between days of gestation

Figure 7: Correlation between placental and endometrial vascular density on day $70(8 \mathrm{~A}), 90(8 \mathrm{~B})$ and 110 (8C). Positive correlations were reduced throughout gestation

Figure 8: Mean values for placental vascular density on days 70, 90 and 110 of gestation. Placental vascular density nearly doubles from day 70 to day 110

Figure 9: Correlation between placental vascular density and placental weight for days 90 and 110 of gestation. The negative relationship was exhibited by day 90 of gestation.

Figure 10: Correlations between placental vascular density and fetal weight for days 90 and 110 of gestation. Relationship was negative and increased from day 90 to day 110 


\section{LIST OF TABLES}

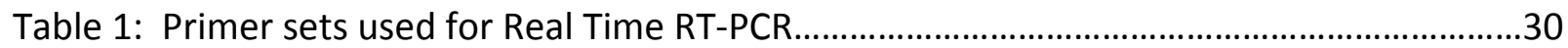




\section{ACKNOWLEDGEMENTS}

Although, this all would not have been possible without the help of many people, I would like to start by thanking my committee members. My major advisor, Dr. Matt Wilson, has been an enormous influence on my education and I thank him for all the help, support and opportunities he has given me. Dr. Ken Blemings, thank you for all of your learning opportunities and input. I want to thank Dr. Kim Barnes for her input and support.

I want to acknowledge Dr. Phil Turk, who spent a tremendous amount of time and effort on the rather complicated statistics for this project. Thank you, your efforts are greatly appreciated!

I would like to thank all of the graduate students in the department for their comaraderie.

Caleb Lemley was an enormous help in the lab and in the writing of this particular document. I thank him not only for this but for all the conversations and laughs. I would like to thank Jill Koch for her efforts during my undergraduate career. I want to thank Stephanie Gatrell for her advice, help and support.

I would like to thank the farm crew, especially Bill Miller for all of his help with the pigs. I would also like to thank my family and friends for their support during my time as a Master's student. Without them this would not have been possible!

Lastly, I would like to thank the International Siblinghood of Professional Placenta Peelers for allowing me the opportunity to become an apprentice and learn the skills needed for placental peeling, which was integral to this work. 


\section{STATEMENT OF THE PROBLEM}

Litter sizes in pig breeds used for production in the U.S. are approximately 9.35 pigs per litter

(NASS, 2009). The Chinese Meishan, imported to the U.S. in the 1980 's, is much more prolific, producing approximately 12-13 pigs per litter; despite having similar ovulation rate, fertility rate and uterine size as our domestic breeds. Efforts to increase litter size in domestic breeds began by increasing ovulation rates. Researchers were able to increase ovulation rates, up to the 22-26 ovulations observed currently, but litter size remained unchanged. Increases in the number of embryos present at the time of elongation resulted in higher embryonic mortality (Dzuik, 1968). Investigation into uterine capacity, simply defined as the number of fetuses that could be gestated within a uterus, and selection for an increase in uterine capacity resulted in a very small increase in litter size.

Investigations into the control of litter size in the Meishan, using the Yorkshire as the control breed, resulted in the transfer of Meishan and Yorkshire embryos into Meishan and/or Yorkshire uterine environments, either as a reciprocal or co-transfer (Wilson et al., 1998; Biensen et al., 1999). When both Meishan and Yorkshire embryos were co-transferred into a common uterine environment, placental size was found to be different between Meishan and Yorkshire fetuses, with Meishans having much smaller placentae. The ratio of fetal weight to placental weight, known as placental efficiency, which describes the amount of fetus that can be grown per gram of placenta, was also found to be different between the two breeds, with Meishans having a higher placental efficiency.

Selection for high placental efficiency was possible and resulted in increased litter size in the Yorkshire (Wilson, 1999). Placental efficiency varies widely both within and among litters, ranging from 5 to 8 at day 110 of gestation. The placentas associated with Meishan pigs are not only smaller (approximately 30\%), but are more vascularized than the placenta associated with Yorkshire piglets. In 1998, Biensen et al. measured placental surface area and placental vascular density in the last third of gestation. Yorkshires, known for their relatively low placental efficiency, had a large increase in 
placental size, but experienced a decrease in placental vascular density. The placenta of the Meishan, known for its relatively high placental efficiency, did not change in placental surface area, but had a dramatic increase in placental vascular density. This difference in placental vascular density was found to account for nearly $50 \%$ of the variation in placental efficiency (Biensen, 1998).

The pig has an epitheliochorial type placenta, which consists of six tissue layers: maternal endothelium, maternal interstitium, maternal epithelium, fetal epithelium, fetal interstitium and fetal endothelium (Perry, 1981). Nutrients that need to be transported from the dam to the fetus must be transported across each of these six layers before entering the fetal blood. The porcine placenta may also be described as diffuse, which means that the placenta attaches nearly uniformly over its entire surface, with the exception of the necrotic tips and the uterine glands. Areolae form over the uterine glands, forming either regular or irregular areolae. In addition to these structures, microvillus structures also exist on the trophectoderm and endometrial cells to aid in the attachment of these to layers in the interareolar space. As gestation proceeds, the placental and endometrial interface will begin to fold, increasing surface area of the placenta without taking up a great deal more space in the uterus. Throughout gestation there is a decrease in the distance between the maternal and fetal blood vessels (Friess, 1980) and therefore a decreased distance for nutrients to be transported across.

Little is known about the expression of nutrient transporters in the placenta and endometrium of the pig. Glucose is the main energy source for the fetus, though amino acids and fatty acids have also been shown to be important in fetal growth (Marconi et al., 1989). However, there have been suggestions that the density of these nutrient transporters in conjunction with the density of vascularity in both the placenta and endometrium may influence the variation in placental efficiency of fetoplacental units within a litter.

Being able to increase litter size without increasing the number of sows, would likely result in higher profitability for the producer. Placental efficiency is an heritable trait, feto-placental units with a 
higher placental efficiency have adapted by either increasing placental size, increasing placental vascular or potentially affecting the nutrient transporter density in the placenta or adjacent endometrium.

Therefore, the objectives of the current work were to characterize the expression of nutrient transporters in both the placental and endometrial tissues for each feto-placental unit within litters on days 70, 90 and 110 of gestation and to observe what relationships existed between this nutrient transporter expression and the placental efficiencies of the feto-placental units. 


\section{REVIEW OF LITERATURE}

\section{Development of the Placenta in the Pig}

By day 10 after fertilization (Figure 1), the porcine conceptuses, now in the blastocyst stage, will have hatched from the zona pellucida and will be distributed evenly along the uterine horns by myometrial contractions. Though the peristaltic contractions continue, the blastocysts will come to rest and will "stick" to the uterine lining. The blastocyst then undergoes elongation, a rapid process in which it will change in shape from a sphere of about $10 \mathrm{~mm}$ in diameter to a filamentous strand of up to one meter in length, although the filamentous conceptus is constrained to only $20-30 \mathrm{~cm}$ of the length of a uterine horn such that individual conceptuses do not overlap (Steven, 1975). The blastocyst can be distinguished into two distinct parts, the trophectoderm and the embryonic disc. The trophectoderm, which is Greek for feeding or nourishing layer, is the portion which will become the outer layer of the placenta. The embryonic disc is the portion of the embryo that will develop into the fetus as well as parts of the placenta. The conceptus will grow until it comes into contact with neighboring conceptuses (Steven, 1975).

After elongation, the blastocyst, containing embryonic disc, trophectoderm and endoderm will begin to acquire a mesoderm layer that "buds" off of the embryonic disc. This mesoderm layer will form exocoelic cavities, allowing it to form two layers: the chorio-vitelline placenta (the layer covering the embryonic disc) and the chorion (the layer which lines the trophectoderm; Steven, 1975). The mesoderm will expand forming amniotic folds that eventually envelope the embryonic disc. As this occurs, the folds will fuse and the amnion, the portion covering the developing embryo, will become separate from the chorion. The allantois will be formed by a protrusion of the hindgut, caudal to the

yolk sac, and will be covered by the mesoderm (Steven, 1975). The allantois will eventually fill the exocoele with the exception of one portion in which the amnion is still in contact with the chorion 
alongside of the embryo. The mesoderm covering the allantois, will fuse with the chorion to form the allanto-chorionic sac that will adhere to the endometrial lining (Steven, 1975). This adherence occurs due to the interlocking of microvilli of the trophectoderm, or chorionic epithelium and the uterine luminal epithelial cells. By day 18, the embryo will form its first adherence and will make all definitive attachments within a day (Figures 2 and 3; Steven, 1975).

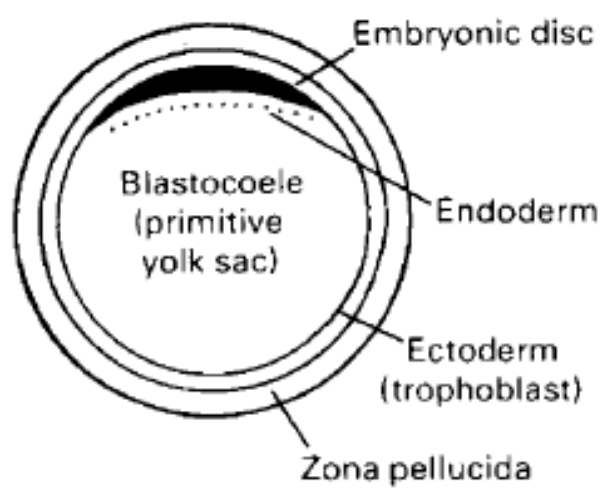

Figure 1. Embryo prior to hatching from zona pellucida (before day 10 of gestation) but before elongation. Perry, 1981.

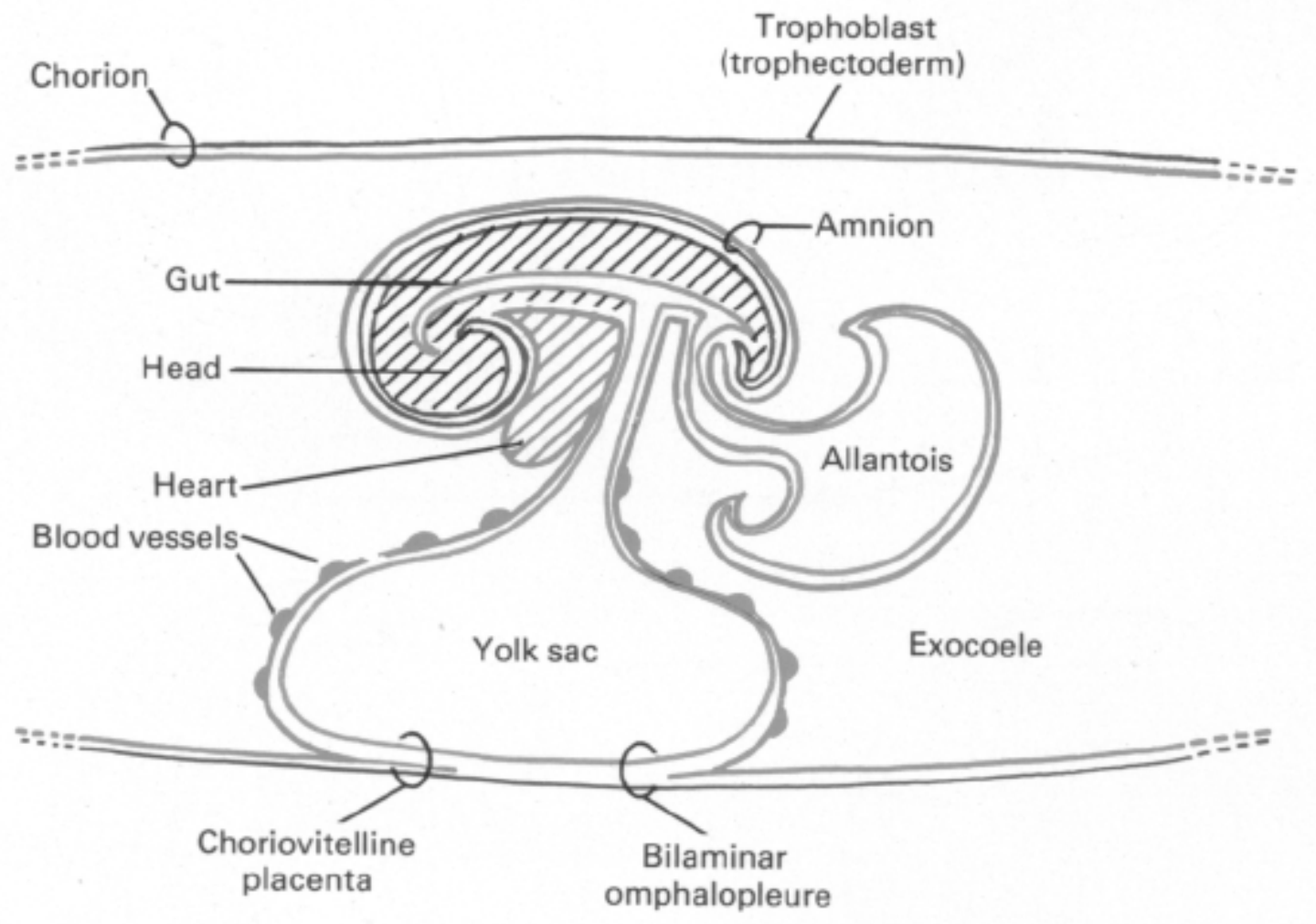

Figure 2. Fetal membranes in the pig at day 18 of gestation. Perry, 1981. 


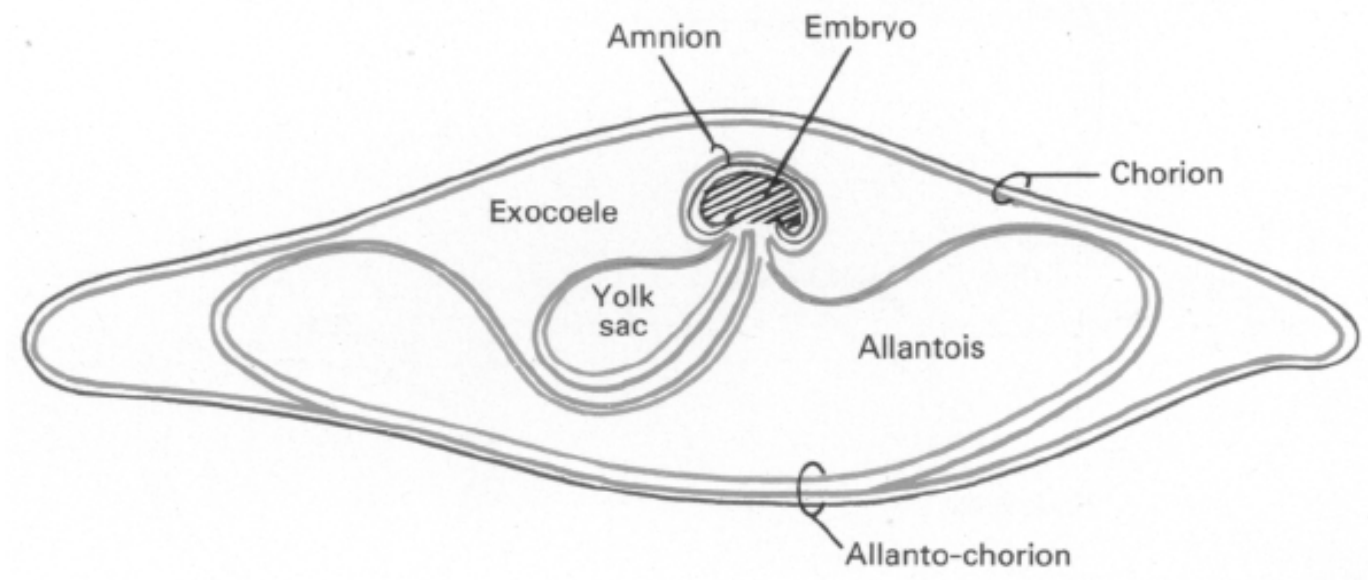

Figure 3. Fetal membranes in the pig at day 21 of gestation. Perry, 1981.

\section{Porcine Placenta}

The placenta of the pig is described as a diffuse placenta. The term diffuse describes the attachment which is nearly uniform over the entire chorionic sac except for the extremities (necrotic tips) and over the openings to uterine glands (Steven, 1975). At the sites of uterine gland openings, areolae are formed around day 18 while the chorion is still vascularized by the allantois (Friess et al., 1982). Around these areolae, the trophoblast cells are modified and the trophectoderm becomes folded forming regular areolae. However, if the maternal epithelial cells become modified, an irregular areola is formed. Including both regular and irregular areolae, as well as the microvillar attachments of the trophectoderm cells and uterine luminal epithelial cells, there are three different structural components in the placenta that allow for nutrient and gas exchange between the dam and fetus.

It is supposed that the areolae, since they cover the uterine gland openings, transfer secretions from these uterine glands to the fetus (Friess et al., 1982). The interaerolar attachment by the interlocking of microvilli offers gaseous, as well as nutrient exchange sites. This attachment allows the placenta and endometrium to stay connected throughout gestation so that fetal and maternal capillaries are in close proximity with each other to facilitate nutrient transfer. As the placenta and fetus grows, the placenta and endometrium will fold into each other forming rugae (primary and secondary) and 
corresponding troughs. This serves to increase surface area, and potentially the nutrient transport capacity, of the placenta. This folding begins to occur at about day 18-20 of gestation and increases in complexity throughout gestation (Friess et al., 1980, 1982). Friess et al. (1980) concluded that gaseous exchange occurs at the summit and lateral sides of the ridges where the capillaries are, while transport of less diffusible compounds occurred near or around the chorionic troughs. This was supported by the discovery of a high number of pinocytotic vesicles in the fetal epithelium of the chorionic troughs.

The porcine placenta, known as epitheliochorial, is the simplest type of placenta and consists of six layers: three from maternal tissues and three from fetal tissues. The layers separating the maternal and fetal blood are the maternal capillary endothelium, maternal connective tissue, maternal (uterine) epithelium, fetal (chorionic) epithelium, fetal connective tissue and fetal endothelium (Steven, 1975). This means that any metabolite being transferred from the dam to the fetus, must be transported across each of these six layers.

Friess et al. (1980) found that around day 30, the distance between maternal and fetal blood is approximately $40 \mu \mathrm{m}$. Throughout gestation, fetal capillaries grow and indent the epithelium on the sides and summits of the ridges, decreasing the cellular height of the epithelial layers and decreasing the distance between the maternal and fetal blood (Friess et al., 1980). Around day 60, the intercellular channels between cells of the maternal epithelium are distinct. By day 100, indentation of both fetal and maternal capillaries is increased, while the height of the cells making up the fetal and maternal epithelium has decreased. There is now a marked decrease in the distance between maternal and fetal blood with less than $2 \mu \mathrm{m}$ separating the structures (Friess et al., 1980). Though intercellular channels were observed in both fetal and maternal epithelium, Friess et al. (1980) did not notice any continuity between these layers after perfusion. 


\section{Piglet Muscle Development}

Not only is the number of pigs born important, but the developmental capabilities of those piglets are also important. It has been suggested that placental size restriction can negatively affect birth weight and the number of secondary muscle fibers, which are more susceptible to environmental changes, such as nutrient availability, than primary fibers (Dwyer et al., 1992; Cerisuelo et al., 2009). Dwyer et al. (1993) also discovered a correlation between the total number of muscle fibers and growth potential of the offspring. Hegarty and Allen (1978) indicated that runts have reduced muscle growth potential and a slower growth rate. Furthermore, Larzul et al. (1997) have shown that the total number of muscle fibers is positively correlated with lean meat percentage. It has also been shown that muscle fiber type may have an effect on meat quality by altering metabolic changes that occur in the conversion from muscle to meat (Karlsson et al., 1999; Franck et al., 2007).

Even when intrauterine crowding, compared to animals that had been subjected to unilateral oviduct ligation, did not affect birth weight, negative impacts on organ development and number and type of muscle fibers were still apparent (Town et al., 2004). In a relatively crowded uterine environment, compared to animals that had unilateral oviduct ligation, the spleen, liver, heart, lungs, kidneys and carcass weights were all decreased; brain weight was not affected (Town et al., 2004). The total number of secondary muscle fibers, muscle weight and the cross sectional area of the semitendonosus muscle were greater in the ligated, or relatively roomy group (Town et al., 2004).

\section{Variation in Litter Sizes}

Among litters, there is great variation in litter size. Potential contributors to this variation include ovulation rate, uterine capacity and uterine environment. Currently, average ovulation rate in maternal line sows is approximately 26 ova per ovulation (Vonnahme et al., 2002). Crowding conceptuses in the uterus by unilateral hysterectomy has resulted in decreased conceptus survival (Christenson et al., 1987; Dziuk, 1968; Monk and Erb, 1974). Increasing ovulation rates may increase the 
number of viable embryos early in gestation, but by day 30 , uterine capacity has become the limiting factor in determining litter size (Fenton et al., 1972).

Christenson et al. (1987) defined uterine capacity as the "maximum number of fetuses that the dam is able to support at a specific stage of gestation". Factors, such as placental surface area, uterine size, and gaseous and nutrient exchange capacity are thought to influence uterine capacity (Dzuik, 1968; Webel and Dziuk, 1974).

Uterine environment, the conditions to which the conceptus is exposed to, can have substantial effects on development. Under and over nutrition of the dam during early gestation can cause a decrease in fetal weight (Redmer et al., 2004). Under nutrition of dams can also contribute to less vigor at birth and a decrease in placental growth (Wu et al., 1998). Particularly, maternal protein deficiency in pigs causes a change in the amino acid profile of maternal and fetal blood and allantoic and amniotic fluids (Wu et al., 1998). Feeding rat dams a low protein diet resulted in fetuses that were lighter and, importantly, had a decreased placental transport of amino acids, especially in transport systems A, $\mathrm{y}^{+}$ and $\mathrm{X}_{\mathrm{AG}}$ (Sibley et al., 1997). It has been reported that an increase in the production and secretion of estradiol 17- $\beta$ can cause an increase in placental weight (Wilson and Ford, 2000; Wilmoth et al., 2009, submitted). Importantly, within in a litter, individual fetal and placental weights vary widely.

Domestic litter size is currently 9.35 pigs per litter (NASS, 2009), but more prolific breeds exist (i.e. Chinese Meishan) that are capable of having three to four more pigs per litter. Furthermore, sows of any breed, including domestic Large White breeds, have 12-14 teats indicating that there is a capacity for these animals to raise 12-14 piglets. These breeds exhibit similar ovulation and fertility rates as well as similar uterine sizes.

There is, however, a reduced estrogen secretion by the trophectoderm at the time of elongation and a reduced length to which the embryos will elongate in the Meishan compared to domestic breeds (Ford and Youngs, 1993). Wilmoth et al. (2009, submitted) treated gilts with exogenous estradiol-17 $\beta$ at 
the time of elongation and observed a near doubling of the proliferation index in the trophectoderm of treated embryos compared to those embryos receiving vehicle. This increase in proliferation of the trophectoderm at the time of elongation could result in a larger placenta at term and the utilization of more space in the uterus, the resulting placental efficiency would also be decreased. A similar treatment of prolific breeds with exogenous estradiol at the time of elongation resulted in a $30 \%$ increase in placental weights and an approximate $40 \%$ increase in surface area with no differences in uterine lengths or weights among treatment groups (Wilson and Ford, 1999).

When reciprocal embryo transfer was performed on Meishan and domestic breeds (Yorkshire), it was determined that uterine environment had an impact on both fetal and placental weights. Meishan conceptuses gestated in a Yorkshire uterus had an increased placental and fetal weight compared to Meishan conceptuses gestated in a Meishan environment. Similarly, Yorkshire conceptuses gestated in a Meishan uterine environment had decreased fetal and placental weights compared to same breed conceptuses gestated in the Yorkshire uterine environment (Wilson et al, 1998).

The majority of fetal growth (90\%) will occur in the last portion of gestation, from day 90 of gestation to term (Redmer et al., 2004). At this time, the fetus will also increase its need for nutrient transport and waste removal. The placenta responds by dramatically increasing in either size, as is the case for the Yorkshire known for its low placental efficiency, or in the density of placental vascularity, as in the Meishan known for high placental efficiency (Biensen et al., 1998; Wilson et al., 1998). This results in placentae from the Meishan being smaller than placentae from domestic breeds.

\section{Placental Efficiency}

Placental efficiency is defined as the ratio of fetal weight divided by placental weight and describes the number of grams of fetus grown on a gram of placenta (Wilson et al., 1998). Placental efficiency has also been shown to be a factor related to the variation in litter size. Individual 
fetoplacental units from the Meishan have a higher placental efficiency than fetoplacental units from domestic breeds.

Wilson et al. (1999) determined placental efficiency of piglets as they were farrowed and selected for placental efficiency. Progeny with both high and low placental efficiencies were selected and animals of the same placental efficiency group were bred. The high placental efficiency group farrowed larger litters and while there was no difference in fetal weights, placental weights were less than those of the low placental efficiency group. This indicates that placental efficiency is heritable and therefore has a genetic basis.

Mesa et al. (2005) were interested in selection for placental efficiency to increase litter size, but were wary of increasing litter size at the expense of piglet birthweight, stillborn births and preweaning mortality. Mesa et al. (2005) chose to select for an index as opposed to selecting solely for placental efficiency. This was due to the evidence that selecting for a trait which is a ratio of positively correlated components puts unequal pressure on the traits, whereas selecting for an index will put predetermined pressure on the individual components (Mesa et al., 2005). The selection index used included total number born in the litter, individual birth and placental weights (which were adjusted for litter size, gestation length and parity) and was designed to allow for more uterine space by decreasing placental size and avoiding the decreases previously seen in birthweight. Highest and lowest indexing females and males (24 and 7, respectively) were chosen for the lines with either high or low placental efficiency, respectively (Mesa et al., 2005). Birthweight, selection index, total born, number born alive, number of stillborns, number of mummified fetuses, number of weanlings, prewearning survival and litter birthweight were not different among lines. Mesa et al. (2005) were able to increase placental efficiency (1.13 times larger) and decrease individual and litter placental weight in the group selected for high placental efficiency. The genetic trend for placental weight was higher in the group selected for low 
placental efficiency (Mesa et al., 2005). Mesa et al. (2005) observed a genetic trend in which lower placental efficiency resulted in larger litter sizes.

\section{Origin of Vascularity}

The vasculature is first present as blood islands in the mesoderm lining the yolk sac, which will develop into blood vessels (Perry, 1981). These blood islands are also present in the mesoderm of the villi, the chorionic membrane and the body stalk, or the precursor to the umbilical cord. The fetal blood vessels in the villi will grow, increasing in size and number, and will eventually merge with the vessels in the body stalk and therefore the fetal blood vessels (Ramsey and Donner, 1980). As the placenta grows and begins to fold forming primary and secondary rugae, these rugae are vascularized to facilitate metabolite exchange. The arterial blood supply reaches fetal capillary tufts at the summit of the rugae, while the venous drainage occurs from the bases of the capillary tufts (Friess et al., 1982).

The maintenance of concentration and thermal gradients is accomplished through different types of blood flow. In concurrent blood flow, the maternal and fetal vessels run side by side and the blood flows in the same direction. This arrangement allows for a maximum of $50 \%$ exchange. In countercurrent blood flow, the maternal and fetal vessels also run alongside each other; however, the blood flow within the vessels is opposite of each other. This arrangement allows for as much as $100 \%$ transfer and is the most efficient type by maintaining a concentration gradient of metabolites (Brocking and Harding, 2001). In crosscurrent blood flow, the maternal and fetal vessels run at 90 degree angles with each other. The maternal blood flow is usually in one direction, while the fetal blood will flow both to and from the maternal vessel (Brocking and Harding, 2001). The relationship between the maternal and fetal blood flow in the pig can be described as cross-countercurrent, containing both cross and counter current properties (Leiser and Dantzer, 1988). Exchange capacity of the placenta increases in the last 30-40 days of gestation, consistent with the presence of both countercurrent and crosscurrent 
blood flow, the development of vasculature on both fetal and maternal sides and the rapid growth of the fetuses (Leiser and Dantzer, 1988).

\section{Placental Efficiency and Vascular Density}

Biensen et al. (1998), while investigating the control of litter size in the Meishan, transferred both Meishan and Yorkshire embryos into both Yorkshire and Meishan recipients. The authors found that the surface area of Yorkshire placentae increased in the last third of gestation while the percentage of vascular density decreased. Conversely, the surface area of Meishan placentae remained statistically the same, while the percentage of placental vascular density dramatically increased. This increase was not only a result of an increased number of blood vessels but an increase in the diameter of blood vessels as well. Endometrial vascular density was also shown to be increased in uteri gestating Meishan conceptuses as opposed to Yorkshire or Yorkshire x Meishan cross conceptuses (Biensen et al., 1999).

Genetic selection for placental efficiency resulted in an increase from day 70 to day 90 in the number of blood vessels per unit area in high as compared to low placental efficiency groups as well as the unselected control group (Vonnahme and Ford, 2003). Vonnahme et al. (2001) found an increased expression of vascular endothelial growth factor (VEGF) mRNA with increasing placental efficiency. VEGF is an angiogenic factor that facilitates endothelium proliferation, migration and capillary permeability upon binding of its receptors, VEGF-R1 and VEGF-R2 (Vonnahme et al., 2001). On day 90, placental mRNA expression of VEGF was greater in the high placental efficiency group than those in the low or unselected groups. The high placental efficiency group also showed an increase in the placental expression of the VEGF receptor 1 and a tendency for an increase in the VEGF receptor 2 (Vonnahme and Ford, 2002). 


\section{Fetal Nutrition}

Fetal nutrition is defined as the supply of nutrients in fetal circulation coming from the placenta (Battaglia and Meschia, 1988). The placenta has transport abilities for amino acids and fatty acids also, but is able to divert all of these nutrients for its own intermediary metabolism before sending them to the fetus (Robertson and Karp, 1976). The placenta supplies all the nutrients (glucose, fatty acid, amino acids and some amino acid precursors) for the fetus and depends on the size, morphology, blood flow and transporter abundance within the placenta (Coan et al., 2008). Increased placental efficiency has been shown to be associated with the enhanced transplacental transfer of nutrients per gram of placenta (Coan et al., 2008). However, there is some fetal de novo synthesis of amino acids and fatty acids, and in late gestation some gluconeogenesis is possible. There have also been reports of fetal consumption of chorioallantoic fluid, the fluid that the fetus is bathed in during gestation (Underwood and Sherman, 2006). Though this fluid does have nutritive properties, its value to the fetus is dependent upon fetal consumption (Underwood and Sherman, 2006).

\section{Glucose}

Glucose is the main energy source, though it is not the sole source of energy, for the fetus (Robertson and Karp, 1976). Glucose accounts for nearly $60 \%$ of the carbon uptake by the placenta and its metabolism is responsible for a large portion of fetal oxygen consumption (Smith and Moe, 1992). The majority of glucose requirements of the fetus are met through placental transport and umbilical circulation (Bell et al., 1999). A concentration gradient is required for the maternal - fetal transfer of glucose (Hay, Jr, 1995). The glucose concentration gradient is a result of lower concentration of glucose in the fetus, equating to about $70 \%$ of that of the maternal glucose concentration (Smith and Moe, 1992). Smith and Moe (1992) also speculated that the lower glucose concentration of the fetus may be a result of a limited transport capacity of the placenta. 
Smith and Moe (1992) reported that the transport capacity, which was found by determining kinetic parameters (placental uptake and egress) and surface area, is much greater than the requirements of the fetus and the placenta. In the second half of gestation in the sheep, when fetal growth is rapid, glucose utilization is also increasing rapidly (Hay, 1995). In response, there is an increase in transport capacity but the magnitude of the gradient remained the same. Battaglia and Meschia (1988) reported that the transfer rate of glucose depends on the surface area available for nutrient transport and insulin concentrations of the dam and the fetus. A reduction in transfer rate is common when placental vessels are occluded and if placental growth is retarded. An increase in insulin in maternal circulation increases the placental transfer of glucose to the fetus. However, the rate of utilization is dependent upon the insulin concentration of the fetus.

Only $30-40 \%$ of the glucose taken up by the feto-placental unit is used by the fetus, the remaining portion is used as fuel for the uteroplacental mass (Battaglia and Meschia, 1988). Glucose will also be used for the production of lactate and fructose. Lactate can be used by the uterus, placenta and fetus, though fructose can only be utilized by the fetus (Battaglia and Meschia, 1988). Lactate and glucose are the main fuels for the fetal heart; whereas the adult heart relies on fatty acids and amino acids as its main sources of fuel (Battaglia and Meschia, 1988).

\section{Amino Acids}

Amino acids are important for the synthesis of peptides, neurotransmitters, nitric oxide, polyamines, carnitine, cell proteins, hormones, nucleotides, creatine and porphyrins as well as being used to make proteins and serving as an energy source (Self et al., 2004). Nitric oxide is an important regulator of angiogenesis and utero-placental blood flow (Gao et al., 2009). Polyamines are important in early embryogenesis and proliferation of tissues, including the placenta (Wu et al., 1998). Amino acids taken up by the fetus are the primary source of amino acids used for protein accretion during growth in utero (Battaglia and Meschia, 1988). Amino acids are transported to the fetus in excess of its protein 
accretion rate, and are likely used as fuels as demonstrated by a high fetal urea production. Amino acids are transported by energy dependent mechanisms usually against the fetal-maternal concentration gradient (Bell et al., 1999). Some amino acids may also be transported by diffusion (Smith and Moe, 1992).

Smith and Moe (1992) looked at the amino acid transporters in the microvillus and basal laminar membranes in the hemochorial placenta of humans. They found that neutral amino acids were transported by systems $A, N$ and $L$ in the microvillus membranes and systems $A, A S C$ and $L$ in the basal laminar membrane. However, some amino acids are synthesized within the placenta. Within both layers, there are sodium dependent and sodium independent systems used for transport.

Anionic amino acids were not transferred from maternal to fetal circulation and were therefore not concentrated in fetal circulation. Instead these amino acids are taken up from these tissues independently using system $X_{A G}^{-}$, which is a sodium dependent transport system. Smith and Moe (1992) also reported that the anionic amino acids glutamate and aspartate were not transported from the dam to the fetus. Battaglia and Meschia (1988) reported that glutamate and aspartate were produced in the fetus and that there was a net transfer of these amino acids from the fetus to the placenta.

Glutamine, a neutral amino acid important for both fetal and placental nutrition, functions to synthesize nucleotides and amino sugars for cell proliferation and differentiation as well as the metabolism of interorgan carbon and nitrogen (Self et al., 2004). The high fetal:maternal ratio observed in porcine placenta indicates that it is synthesized by the placenta via de novo synthesis.

Leucine, an essential amino acid, may be rate limiting for growth of porcine fetuses. Leucine is transported by System L sodium independent and dependent transporters. At day 100 of gestation, there is a marked decrease in the concentrations of leucine in fetal plasma (Finch et al., 2004). There is also a marked decrease in leucine flux to the placenta in cases of intrauterine growth restriction (Finch et al., 2004). Finch et al. (2004) measured the uptake and sodium dependence on transport of leucine 
in small and average sized fetuses at day 45, 65 and 100 of gestation. Total uptake of leucine decreased at day 45 in the placenta supplying the smallest fetus, but no difference was detected at days 65 or 100 (Finch et al., 2004). In both small and average sized fetuses on days 45 and 65, leucine transport was predominantly sodium independent. However, on day 100 , leucine transport in average sized fetuses was $50 \%$ sodium independent and $50 \%$ sodium dependent. This was not observed in the small fetuses and indicates that the placenta supplying these small fetuses may be developmentally delayed (Finch et al., 2004).

Cationic amino acids, however, were found to be concentrated in the fetal circulation and the placenta (Smith and Moe, 1992). Systems $\mathrm{b}^{0,+}$ and $\mathrm{y}^{+}$were found in the basal lamina membrane and responsible for the transport of these amino acids. Both of these systems are sodium independent. Arginine, a cationic amino acid, is known as a precursor for nitric oxide and polyamines. It is the most abundant nitrogen carrier in fetal pigs and one of the most abundant amino acids in fetal tissues (Mateo, et al., 2007). Nitric oxide enhances blood flow in sheep and is therefore an important regulator of the rate of transfer of nutrients from the dam to the fetus (Gao et al., 2009). Polyamines are important for embryogenesis and placental growth, both nitric oxide and polyamines are important for angiogenesis (Mateo et al., 2007). When dams were fed diets high in dietary L-arginine, the total number of piglets born alive and the total litter birthweight based on the number born alive increased by 22 and 24\%, respectively (Mateo et al., 2007). Also in the arginine fed gilts, the concentrations of proline, ornithine and arginine were elevated for days 70, 90 and 110 (Mateo et al., 2007). Mateo et al. (2007) believes this increase in number born alive and litter weight are a result of increased angiogenesis and growth as well as an increase in transport across the placenta, which is mediated by the sodium independent system $\mathrm{y}^{+}$cationic amino acid transporters (CAT) one, two and three (Gao et al., 2009), but feeding a diet deficient in arginine may also limit the synthesis of some proteins. 
According to Gao et al. (2009) arginine is increased 10-fold in the uterine lumen of sheep between days 10 and 15 of gestation, which is the time period in which the blastocyst will undergo elongation. Particularly of interest, Gao et al. (2009) found that in sheep, CAT-1 was most abundant around days $16-20$ of pregnancy and days 13-18 in conceptuses. Coan et al. (2008) examined the heaviest and lightest placenta from litters of mice and measured the unidirectional transfer of radiolabelled inulin, glucose and methyl-amino isobutyrate (MeAIB). Where inulin and glucose was not different between the lightest and heaviest placenta within a litter, MeAIB was greater per gram of placenta of the lightest compared to the heaviest placenta (Coan et al., 2008).

\section{Lipids}

Fatty acids are important for energy transduction and storage, synthesis of phospholipids and structural components as well as being precursors for prostaglandins and thromboxanes (Hajri and Abumrab, 2002). They also regulate numerous enzymes, expression of genes involved in fatty acid metabolism and have important roles in the nervous system and synapses (Hajri and Abumrab, 2002). The porcine neonate has little body lipid (10-30 g total lipid/ kg body weight; Manners and McCrea, 1963; Farnworth and Karmer, 1987). The fetus obtains fatty acids through the placenta and through de novo synthesis in the liver (prepartum) and adipose tissue (post partum; Leskanich and Noble, 1999). However, de novo synthesis relies on free fatty acids and therefore the mobilization of these free fatty acids from triacylglycerol, which is accomplished in adipose tissue of which the fetus has very little. This de novo synthesis is the primary source of fatty acids for the fetus because transfer across the placenta is low. Though transport of fatty acids is low, concentrations of polyunsaturated fatty acids (PUFA) are greater in the fetal brain and liver than in the maternal liver due to de novo synthesis (Leskanich and Noble, 1999). 


\section{Fetal Fluids}

The fluid that the fetus is submerged in in utero, known as amniotic fluid, is full of nutrients, especially amino acids and proteins, and has similar qualities of human breast milk (Underwood and Sherman, 2006). There are two subsets of this fluid, amniotic fluid which is produced from both the fetus and the mother and is what the fetus bathes in within the amnion (Wu et al., 1995) and allantioc fluid, which is located outside the amnion. Fetal swallowing of the amniotic fluid is common and meets $10-14 \%$ of the fetal nutrient requirement (Underwood and Sherman, 2006). Not only does it serve as a source of nutrition for the fetus, but amniotic fluid enhances gastrointestinal development in those fetuses that swallow it compared to those that do not (Underwood and Sherman, 2006). Glucose content of amniotic fluid decreased in the third trimester of humans (Underwood and Sherman, 2006). At the end of gestation, there is an increase in the concentrations of cholesterol and glyceride in amniotic fluid suggesting that the fluid has the potential to supply and degrade lipids (Underwood and Sherman, 2006).

Glutamine and arginine are both found in amniotic fluid, glutamine is important for gastrointestinal growth and function as well as cell differentiation and proliferation. Arginine is important for blood flow to the developing intestines (Underwood and Sherman, 2006). In pigs, glutamine is the most predominant amino acid in amniotic fluid for the first three months of gestation, but by day 110 alanine is the most abundant (Wu et al., 1995). Citrulline, the precursor for arginine, increases during the first three months, but arginine, glutamine, lysine and ornithine decrease after day 45 (Wu et al., 1995). In allantoic fluid, glycine is the most abundant amino acid at day 30, but decreases thereafter (Wu et al., 1995). However, ornithine and arginine become the most abundant on day 45 and 60 and decrease thereafter and glycine becomes the most predominant again (Wu et al., 1995). This decrease in the allantoic fluid volume is coincident with the period of rapid placental growth (Mateo et al., 2007). 


\section{Regulation of Transport}

Glucose transport is regulated by a number of things. Regulation of the maternal glucose concentration is very important since it will be supplying not only the dam, but also the fetus. In this instance, it is important to not let the fetus become a parasite to the dam. This is done through increases in the rates of maternal glucose production and the development of glucose intolerance and insulin resistance of the dam. The fetal pancreas also begins producing insulin, which will enhance glucose utilization by the fetus (Hay, 2006). Transporters are the main regulators of glucose uptake by the fetus. Their expression changes according to acute and chronic changes in the glucose supply (Hay, 2006). Regulation of amino acid transporters by the cell is accomplished three different ways: synthesis of a protein that is rate limiting to transport which causes an increase in the $V_{\max }$ of the transporter (Smith and Depper, 1974); transinhibition, which is a feedback system where an intracellular substrate binds to the transporter and does not allow for uptake of the amino acid; and insulin, though only in the case of muscle (Smith and Moe, 1992). Insulin also enhances de novo synthesis of fatty acids. Growth hormone has an inhibitory effect on de novo synthesis of fatty acids (Leskanich and Noble, 1999). Lipoprotein lipase, which degrades triacylglycerol into glycerol and free fatty acids, is only found in the maternal facing membranes of the placenta. Since only fatty acids, not triacylglycerol, can be transported across tissues this is likely to prevent the transport of the NEFAs from the fetus to the mother after hydrolysis (Thomas et al., 1984).

\section{Placental Metabolism of Nutrients}

The placenta, because it is such a rapidly growing and highly vascularized organ, uses some of the nutrients being delivered from the dam for its own growth and energy needs. The placenta utilizes a great deal of the glucose being transferred from the dam to the fetus, with the fetus only taking up 3040\% (Battaglia and Meschia, 1988). Evidence that the placenta metabolizes amino acids lies in the results of Holzman et al. (1977 and 1979) who found that the human and sheep placenta produced 
ammonia and that a fraction of this ammonia was taken up and metabolized by the fetal liver (Battaglia and Meschia, 1988).

Lipid concentrations in both the fetal and maternal portions of the placenta remained unchanged after the dam was fed a diet high in tallow (Ramsay et al., 1991). This indicated that though the placenta helps with the transfer of lipids through esterification of fatty acids, its provisioning does not require storage of lipids (Leskanich and Noble, 1999). Further evidence of this is that placenta associated with low birth weight babies had vascular lesions and inflammation due to decreased blood flow because of a deficiency in long chain fatty acids (Crawford et al., 1989). Dyck and McKay (1986) found that the variation in fetal weight was mostly related to the uterine weight in the area of the placental attachment.

\section{Transport of Substrates}

\section{Glucose}

Glucose is transported across the placenta using a family of transporters, GLUT, named for the order in which they were cloned. GLUT-1 and GLUT-3 are most prevalent the in placenta. GLUT-1 is the primary transporter in all species and transports glucose by facilitative transport proteins (Hay, 1995). GLUT-3 has been shown to be significant in the sheep, rat and human (Hay, 2006). GLUT-1 is located on both the fetal and maternal facing portions of the placenta, allowing for bi-directional transport of glucose. GLUT-3, however, is only found on the maternal facing portion and has the proposed function of supplying the trophoblast portion of the placenta with glucose (Hay, 2006).

\section{Amino Acids}

System $A$ is a sodium dependent transporter specific for neutral amino acids with short branched side chains, such as alanine and glycine (Sibley et al, 1997). System $\mathrm{y}^{+}$transports cationic amino acids, located in the microvillus and basal layers of the rat placenta. System $\mathrm{X}_{\mathrm{AG}}^{-}$transports anionic amino acids and is located in the basal layer of the rat placenta (Sibley et al, 1997). 
Branched chain amino acids from maternal circulation are transaminated to form branched chain ketoacids and glutamate, which is a precursor for glutamine (Self et al., 2004). The human and ovine placenta are known to have high branched chain amino acid aminotransferase activity (Jaroszewicz et al., 1971; Goodwin et al., 1987). Glutamine synthetase, the enzyme that converts glutamate to glutamine, activity is high in the rat placenta (Remesar et al., 1980).

Fatty Acids

Since most tissues contain no capacity to synthesize fatty acids, the needed amount of fatty acids must be taken up from circulation (Hajri and Abumrab, 2002). There is still a great deal of debate about whether fatty acids are taken up by cells via diffusion or protein facilitated transport (Hui and Bernlohr, 1997). The contribution of each of these methods to fatty acid transport is dependent upon the concentration and molar ratios of fatty acids and albumin in circulation (Hajri and Abumrab, 2002). To date, five fatty acid transport proteins have been discovered: Plasma Membrane Fatty Acid Binding Protein (FABPpm); Caveolin; Fatty Acid Translocase (FAT); Fatty Acid Transport Protein (FATP); and an unnamed $56 \mathrm{kD}$ protein (Hui and Bernlohr, 1997). Of all of these transporters, FAT, which was discovered in 1984 by Abumrad et al., has been investigated the most (Hajri and Abumrab, 2002). FAT reversibly binds long chain fatty acids, such as stearate, oleate, arachidonate, palmitate and lineolate, in a ratio of 3 moles of fatty acids to 1 mole of FAT (Hui and Bernlohr, 1997). FAT is highly expressed in cardiac and skeletal muscle, intestines, spleen and adipose tissue (Hui and Bernlohr, 1997). Increased fatty acid uptake upregulates FAT expression (Hui and Bernlohr, 1997).

FAT has high homology with the human gene CD36 (Hajri and Abumrab, 2002). CD36 is an integral membrane protein that is expressed on the surface of the cell as well as within the lysosomes of the cell (Hajri and Abumrab, 2002). It is a facilitator of membrane fatty acid transport by muscle and adipose tissues (Hajri and Abumrab, 2002). CD36 is a marker of preadipocyte differentiation into adipocytes and is regulated by peroxisome proliferative-activated receptors (PPAR). Mice null for CD36 
have a $60 \%$ decrease in fatty acid uptake and a coincident decrease in fatty acid oxidation (Coburn et al., 2000).

Fatty acids, circulating in the maternal plasma as triacylglycerols are transferred through the placenta in the non-esterified fatty acid (NEFA) form (Leskanich and Noble, 1999). Only triacylglycerols in very low density lipoproteins are hydrolyzed in the placenta, this is thought to be a mechanism to protect the fetus from changes in dietary protein and to facilitate an increase in the delivery of long chain PUFAs (Dutta-Roy et al., 1996). This conversion from triacylglyercol to free fatty acids is done with the enzyme lipoprotein lipase which has been found to have high activity in the placenta (Ramsay, 1991). This activity increases from early to late gestation with the perception that this is due to the increase in fetal demand for NEFAs (Thomas and Lowy, 1987). In fetal plasma, NEFA's are bound to albumin or $\alpha$-fetoprotein (Brossard et al., 1997; Innis, 1991).

The rate of transfer of fatty acids to the fetus depends on the fatty acid composition, the (re)esterification step and the limitations of fatty acid binding protein (Leskavich and Noble, 1999). The epitheliochorial type placenta of sheep, cows and pigs, are less permeable to free fatty acids than the hemochorial placenta of humans and rabbits (Battaglia and Meschia, 1988). During undernutrition of the dam, the uterus will take up ketone bodies but not free fatty acids (Battaglia and Meshcia, 1988).

\section{Concerns of Modern Genotypes}

Through years of trying to determine why litter size in domestic breeds is not similar to the capacity to have larger litters, pigs have been selected for increased ovulation rate, increased uterine capacity, increased uterine size and increased body size of females, just to name a few. The problem with this is that we now have gilts and sows that ovulate approximately 26 ova (Vonnahme et al., 2002), but still have litters of approximately 9.5 piglets per litter (NASS, 2009). Unilateral hysterectomy induces a crowded uterine environment which provides a good model for studying intrauterine growth retardation. In this situation, embryo survival at the time of elongation is greatly reduced due to space 
restriction and the placentae cannot all grow to the same extent, therefore some fetuses are exposed to more nutrients and gases than others. How efficient the placenta can be at transporting nutrients from the maternal blood supply, despite its size can make a huge difference in piglet size and development, both pre- and post-natal.

The ability of the placenta to transport nutrients to the fetus is primarily dependent upon two things: 1) the size of the placenta and 2) the blood flow to the utero-placental unit. The size of the placenta is important because the site of nutrient exchange is greater and the more space that is available leads to a greater potential for an increased abundance of nutrient transporters. The amount of blood flowing to the fetus will allow a greater potential for nutrient delivery so that the nutrients may be transported across the placenta and to the fetus. 


\title{
FACTORS CONTRIBUTING TO THE VARIATION IN PLACENTAL EFFICIENCY ON DAYS 70, 90 AND 110 OF GESTATION IN GILTS
}

\author{
T.A. Wilmoth, C.O. Lemley, P. Turk, and M.E. Wilson \\ Division of Animal and Nutritional Sciences, Davis College of Agriculture, Forestry and \\ Consumer Sciences, West Virginia University Morgantown, West Virginia, USA
}

Address all correspondence and requests for reprints to: Matthew E. Wilson, Ph.D., Division of Animal and Nutritional Sciences, Davis College of Agriculture, Forestry and Consumer Sciences, West Virginia University, P.O. Box 6108, Room G048, Morgantown, West Virginia 26506. E-mail: mwilso25@wvu.edu

This work is published with the approval of the Director of West Virginia Agriculture and Forestry Experiment Station as scientific paper /. This project was supported by Hatch project 468 (NCERA 057).

Key Words: nutrient transport, pigs, placental efficiency, vascular density 


\section{Abstract}

Placental efficiency (fetal weight divided by placental weight) is related to litter size, with increased placental efficiencies associated with larger litters. The ability of the placenta to supply the fetus with nutrients from the maternal blood supply depends on both the vascularity of the placenta, the size of the placenta and the density of transporters. The objectives of this experiment were to determine the mRNA expression of nutrient transporters in both the placenta and adjacent endometrium and to see if a relationship existed between placental efficiency and nutrient transporters and vascular densities. Gilts were randomly selected to be ovario-hysterectomized on days 70, 90 or 110 of gestation. At the time of ovario-hysterectomy, placental and endometrial samples were collected. Numerous fetal variables were also recorded at this time, including placental efficiency, fetal weight, placental weight and litter size. Litter size was 11.1 pigs per litter and ovulation rate was 15.8. Placental efficiency and the range of placental efficiencies both within and among litters increased throughout gestation. Placental vascular density and endometrial vascular density were positively correlated for day 70, 90 and 110 of gestation. Placental vascular density was shown to be related to placental weight and fetal weight at days 90 and 110 . The statistical model used accounted for variation among litters and within litters revealing that significant variation existed both among and within litters and that the variation was largely affected by day of gestation. However, no relationships were observed between placental efficiency and the RNA message for nutrient transporters or vascular density. No interactions existed between day of gestation and the nutrient transporter expression. The relationships between placental efficiency and placental weight and fetal weight were also similar to previous observations. However, no relationship existed between the placental efficiency and placental vascular density when examined for each day separately. The absence of a relationship between placental efficiency and nutrient transporter and vascular densities may be attributed to modern 
genotypes being bred to produce larger litters. We also only measured the mRNA expression of nutrient transporters, which may also explain the lack of relationship with placental efficiency.

Key Words: nutrient transport, pigs, placental efficiency, vascular density 


\section{Introduction}

Litter sizes of domestic commercial pig breeds are smaller than those of more prolific breeds, such as the Chinese Meishan (9.5 piglets per litter versus 13, respectively). Though uterine size is similar, uterine capacity is different with the more prolific breeds having a greater uterine capacity. Uterine capacity is defined as the number of fetuses that a female can gestate within a uterus (Christenson et al., 1987). Placental surface area, uterine size and gaseous and nutrient exchange are all thought to influence uterine capacity (Dzuik, 1968). In fact, Biensen et al. (1999) found a difference in the ratio of fetal weight to placental weight (placental efficiency) with the more prolific breeds having a higher placental efficiency than the commercial breeds.

Variation in placental efficiency occurs both among litters and within an individual litter. This variation can be great, a portion of which is attributed to differences in the vascular density of the placenta and adjacent endometrium (Biensen et al., 1999). However, vascular density does not completely describe all of the variation in placental efficiency.

In the pig, nutrients passing from maternal blood must be transported across six layers of tissue to enter fetal blood. The supply of nutrients to the fetus will depend upon the transport capacity of the placenta, which is defined by the amount of vascularity and nutrient transporters in the placenta and adjacent endometrium (Coan et al., 2008). Therefore, the objectives of the current experiment were to determine the mRNA expression of nutrient transporters in the placenta and adjacent endometrium of pigs at day 70,90, and 110 of gestation and to model whether placental efficiency could be described by vascularity and nutrient transporter expression. 


\section{Materials and Methods}

\section{Animals}

At approximately six months of age, gilts ( $N=19)$ from a maternal line (PIC 1025) were observed for estrous behavior. They were allowed to cycle once and were bred by artificial insemination using maternal PIC line 1025 semen (Birchwood Genetics, West Manchester, OH), 12 and 24 hours following the detection of their second estrus. At the time of breeding, gilts were randomly assigned to be ovariohysterectomized on day $70(n=6), 90(n=7)$, or $110(n=6)$ of gestation. Gilts were allowed to gestate normally until the time of their assigned ovario-hysterectomy.

Approximately 48-72 hours before the gilts were to be ovario-hysterectomized, gilts were moved to the Food Animal Research Facility (FARF) at the West Virginia University Animal Science Farm. All food was withdrawn for 12-24 hours prior to surgery and water was withdrawn 12 hours before surgery. All animal work was completed in accordance with the West Virginia University Animal Care and Use Committee (ACUC \# 07-1203).

\section{Surgeries}

At the time of surgery, a blood sample was collected and anesthesia was induced by the administration of xylazine $(2 \mathrm{mg} / \mathrm{kg})$ and ketamine $(3 \mathrm{mg} / \mathrm{kg})$ via jugular venipuncture. The gilt was fitted with a mask that covered the snout and maxillary portion of the jaw. The mask was taped to the mandibular portion of the jaw to keep it in place. The gilt was maintained on anesthesia using isofluorane, to effect. Atropine $(0.05 \mathrm{mg} / \mathrm{kg})$ and penicillin $(10 \mathrm{cc})$ were administered intramuscularly. The gilt was placed in dorsal recumbency so the surgical area could be prepped for surgery.

The gilt was covered with a surgical drape. The gravid uterus was exteriorized through a midventral incision. The main uterine arteries and uterine branches of the vaginal arteries were ligated with a locking stitch and the cervix was ligated and transsected. The uterus was removed and gravid uterine weight was recorded. The ovaries and broad ligaments were removed and the number of 
ovulations was determined by dissecting out and counting the number of corpora lutea. The uterus was then opened by cutting along the antimesometrial sides of the uterine horns. The umbilicus of each feto-placental unit was tagged with two tags labeled with the uterine horn (right, R, or left, L) and the piglet number with one being the fetus closest to the oviduct. The umbilical cord was cut between the two tags and the fetus removed and weighed. Fetal livers and hearts were removed and weighed.

With the uterus lying open, a sample (approximately $6.5 \mathrm{~cm}^{2}$ ) of all tissue layers (placenta, endometrium and myometrium) was collected and placed in tissue cassettes and fixed in neutral buffered formalin. Placentas were peeled away from the endometrium and weighed. At this time, samples were taken from both the placenta and the endometrium, placed in cryovials and snap frozen in liquid nitrogen. Placental efficiency was determined for each feto-placental unit.

\section{Determination of the mRNA Expression of Nutrient Transporters}

RNA was extracted using TRIzol reagent (Invitrogen, Carlsbad, CA). For each $\mathrm{mL}$ of Trizol, either 0.2 or $0.1 \mathrm{~g}$ of placental or endometrial tissue was used, respectively. RNA was precipitated using 2propanol and reconstituted with $20 \mu \mathrm{L}$ of nuclease free water. RNA concentration and $A_{260} / A_{280}$ ratio was determined using a NanoDropper ND-1000 spectrophotometer. RNA was electrophoresed through a $1.5 \%$ agarose gel to determine sample purity and to visualize $18 \mathrm{~S}$ and $28 \mathrm{~S}$ rRNA bands.

Real Time RT- PCR was performed as previously described (Costine et al., 2007). Samples were reverse transcribed using moloney murine leukemia virus reverse transcriptase (Promega, Madison, WI). Acidic ribosomal protein (ARP) was used as the housekeeping gene. Nutrient transporters investigated included a glucose transporter (GLUT-3), fatty acid translocase (FAT-1 and FAT-2), cationic amino acid transporter (CAT-1), alanine, serine and cysteine transporter (ASCT-1), y $+\mathrm{L}$ amino acid transprter (yLAT1) and $\mathrm{b}^{0,+}$ amino acid transporter (rBAT-1). Primer sequences for GLUT-3, FAT-1, FAT-2, CAT-1, ASCT-1, yLAT-1 and rBAT-1 (Integrated DNA Technologies, Inc., Coralville, IA) are shown in Table 1. Relative mRNA expression of nutrient transporters were corrected for PCR efficiency and standardized using ARP 
and expressed relative to a pooled sample. Annealing temperatures and efficiencies for each gene are shown in Table 1.

Table 1: Primer Sets for Real Time RT-PCR.

\begin{tabular}{cccccc}
\hline & & & & & \multicolumn{2}{c}{ Theoretical } \\
Gene & Accession No. & Forward Primer & Reverse Primer & Efficiency & Yield \\
\hline GLUT-3 & & CTCTTGGGCTTCACCATCAT & CAGGAACCGAGGACTTTCAG & 1.70 & $85 \%$ \\
FAT-1 & DQ192231 & CAGTGGGTTGGGTAAGTGT & ACATTCAACAGGCTGGAACC & 1.66 & $83 \%$ \\
FAT-2 & AY822678 & CCGGAGGAAAGACTCAGACA & CCACCGGAAAGTATCTCCAA & 1.80 & $90 \%$ \\
ASCT-1 & EU155140 & CCGGGATGGCTTACTGTTTA & ACGAGAGCCTTCAGGTCAAA & 1.73 & $87 \%$ \\
CAT-1 & NM_001012613 & ATGGCCTTCCTCTTTGACCT & GGCTGGTACCGTAAGACCAA & 1.88 & $94 \%$ \\
rBAT-1 & NM_001123042 & ATCTCCATCATCGCCATCTC & TCGCTGTCCTTGAAAGACCT & 1.78 & $89 \%$ \\
YLAT-1 & NM_001110421 & CATCTTAACCAACGTGGCCT & GGTCTGCAAAAGTCACAGCA & 1.76 & $88 \%$ \\
ARP & & GCTAAGGTGCTCGGTTCTTC & GTGCGGACCAATGCTAGG & 1.75 & $88 \%$
\end{tabular}

\section{Determining Vascular Density}

Tissue cross sections containing placenta, endometrium and myometrium, were fixed in formalin, dehydrated by a series of alcohols and finally embedded in paraffin (Paraplast Plus, Fisher Scientific). Embedded tissues were sectioned at $5 \mu \mathrm{m}$ and fixed to glass slides (Columbus Serum Co., Columbus, $\mathrm{OH}$ ). One section for each fetus was stained using periodic acid and Schiff's reagents and counterstained using hematoxylin. For each section, two separate microscopic fields were visualized and captured (Retiga, Qimaging 2000R, Surrey, BC, Canada) along the placental endometrial interface. Secondary rugae were visualized under 20x magnification. All placental and endometrial tissues were outlined separately within an individual visual field. The total number of vessels, total area of vessels, total area selected and the percentage of vessels was computed by Northern Eclipse (Empix Inc., North Tonawanda, NY) software. Data from the two different images for both placental and endometrial 
tissues were averaged. Vascular density was determined separately for both the placental and endometrial tissues by the software.

\section{Statistical Analysis}

The cluster-randomized trial study design generated a two-level clustered data set where the litters were considered as randomly sampled clusters (level 2) and the feto-placental units were the unit of analysis (level 1). A multilevel model was used to model placental efficiency; specifically, a two-level random intercept model was used. Level 2 covariates were day and litter size with level 1 covariates being the 1 other numerical predictors (e.g. vascular density and nutrient transporter expression). The initial model consisted of two components. The level 1 model was:

Peff $_{i j}=b_{1 j}$ Pglut $3 i j+\ldots+b_{16 j} E D_{i j}+\varepsilon_{i j}$

where $\varepsilon_{i j} \sim N\left(0, \sigma^{2}\right)$ for $I=1, \ldots ., 191$ piglets and $\mathrm{j}=1, \ldots, 19$ litters. Note $\varepsilon_{i j}$ denotes the error or withinlitter, variance. The level two model was:

$$
\begin{aligned}
& b_{0 j}=B_{0}+b_{1} \times \text { Day } 70_{j}+b_{2} \times \text { Day90 }_{j}+b_{3} \times \text { Litsize }_{j}+u_{j}
\end{aligned}
$$

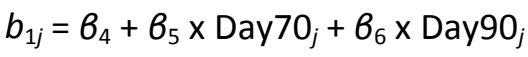

$$
\begin{aligned}
& b_{16 j}=\beta_{49}+b_{50} \times \text { Day } 70_{j}+B_{51} \times{\text { Day } 90_{j}}
\end{aligned}
$$

where $u_{j} \sim N\left(0, \sigma_{\text {litter }}^{2}\right)$ were the random litter effects with variance $\sigma_{\text {litter. }}^{2}$

Numerical predictor variables were log base 2 transformed to reduce large leverage points and centered primarily to reduce multicollinearity. Only interaction terms including day were included in the initial model due to the importance of day and due to the large number of possible interaction terms.

We borrow heavily on the model building strategies of West et al., 2007. In summary, we specify the initial model, select a structure for the random effects in the model, select a covariance 
structure for the errors in the model, and then reduce the initial model by removing nonsignificant fixed effects, test the main effects associated with treatment, and assess model diagnostics. All analysis was done using SAS Proc Mixed (Version 9.2).

We fit the initial model with and without the random litter effects and use a restricted maximum likelihood-based likelihood ratio test (REML LRT) to test if the variation between litters was the same. The null distribution of the test statistic is a simple mixture of chi-squared distributions, with 0 and 1 degrees of freedom (Verbeke and Molenberghs, 2000). Essentially, this tests whether the random litter effects associated with the intercept should be omitted from the initial model. Subsequent tests to select a covariance structure for the errors will be discussed in the results as they arise.

In order to reduce the initial model, we used the model building strategy as set forth in Milliken and Johnson (2002). Corresponding to their "slopes equal to 0" step, we test the hypothesis that there is no linear association between placental efficiency and the numerical predictor variables (including litter size) for any of the three levels of day. This amounts to fitting the initial model without any main effects corresponding to the numerical predictor variables and examining the $F$-tests for fixed interaction effects. Subsequent tests to reduce the initial model are best discussed in the results as they arise.

The final model yielded estimates of the least-squares mean placental efficiencies, variance intraclass correlations and (adjusted) intraclass correlation coefficients. For the model specified here, the litter from a given group (West et al., 2007) is defined to be the litter variance component divided by the total of the litter and error variance components.

Extensive residual and influence diagnostics were run and checked to validate the assumptions of the final model (Schabenberger, 2004). 


\section{Results}

Litter size did not differ for days 70,90 and $110(10.2 \pm 1.1,13 \pm 0.7,9.7 \pm 1.3$, respectively) with an average litter size of 11.1 pigs per litter. Average ovulation rate was 15.8 , which also did not differ with day of gestation (day 70, $17 \pm 1.2$; day $90,15 \pm 1.5$; day $110,15.5 \pm 1.0$ ). Placental efficiency increased $(P<0.001)$ throughout gestation (day 70, $1.8 \pm 0.4$; day $90,3.7 \pm 0.8$; day $110,5.7 \pm 0.8$; Figure 1) and importantly the range of placental efficiency increased from day 70 to 90 and was similar between day 90 and 110 (day 70, $1.03-2.64$, range of 1.61; day 90, $2.13-6.23$, range of 4.1; day 110, $4.11-7.46$, range of 3.35; Figure 2).

We retained the random effects associated with litter-specific intercepts in the initial model and in all subsequent models.

Placental efficiency exhibited a linear trend with day of gestation and was also different on day of gestation particularly a smaller variation in placental efficiency was observed on day 70 compared to day 90 and 110. We fit a model with separate error variances for each level of day. A second REML LRT tests if the error variance is constant among the three days. Variation among day of gestation was different and therefore an appropriate model is one with heterogeneous error variances.

The next REML LRT is done to see if the error variances for day 90 and 110 can be combined. There was insufficient evidence to suggest that the two variances in question were not different and were combined.

The last REML LRT used to specify the covariance structure of the errors is done to see if the error variances for the "pooled" days and day 70 are equal. Therefore a pooled error variance for the day 90 and 110 treatments was used within the heterogeneous error variance structure.

With respect to the model reduction portion of the analysis, there was no evidence of any linear association between placental efficiency and the numerical predictor variables (including litter size) for any of the three levels of day using the Holm step-down procedure. The mean placental efficiencies 
differ by level of day, after controlling for all other numerical predictor variables, and the random litter effects.

Means and significances among fetal weights, placental weights and placental efficiencies were determined using the Least Square Means in the GLM procedure of SAS. Correlations among placental efficiency, placental weight, fetal weights and vascular density were determined using the correlation procedure of SAS.

Fetal weight and placental weights were positively correlated for day 70, 90 and $110(r=0.78, r=$ 0.77 and $r=0.85 ; P<0.0001 ;$ Figure 3a-c). Placental weight was negatively correlated with placental efficiency for all days of gestation, though the magnitude of the relationship was reduced at day 110 (day 70, $r=-0.84, P<0.0001$; day $90, r=-0.81, P<0.0001$; day $110, r=-0.44, P<0.001$; Figure 4a-c). Liver weights increased for day 70,90 and 110 of gestation $(7.41 \pm 1.95 ; 16.79 \pm 3.66 ; 39.14 \pm 10.70$, respectively; $P<0.0001$, Figure 5). Heart weights also increased throughout gestation (day 70, $1.64 \pm$ 0.37; day 90, $4.85 \pm 0.86 ;$ day $110,10.85 \pm 2.74 ; P<0.0001$, Figure 6).

There was a positive relationship between the vascular density measured in the placenta and the vascular density measured in the endometrium for all days of gestation (day $70, r=0.55, P<0.0001$; day $90, r=0.55, P<0.0001$; day $110, r=0.38, P<0.0032$; Figure $7 a-c)$. Placental vascular density nearly doubled from day 70 to 110 (1.18 \pm 0.76 and $2.94 \pm 2.11$, respectively; Figure 8$)$. The vascular density of the placenta also had significant relationships with placental weight and fetal weight, though these relationships weren't evident until day 90 and 110 . Placental vascular density was negatively correlated with placental weight and this relationship became stronger from day 90 to day 110 (day $90, r=-0.24, P$ $<0.02$; day $110, r=-0.51, P<0.0001 ;$ Figure $9 a, b)$. Placental vascular density was also negatively correlated with fetal weight, and this relationship also became more pronounced from day 90 to 110 (day 90, $r=-0.30, P=0.0045 ;$ day $110, r=-0.58, P<0.0001 ;$ Figure 10a,b). 


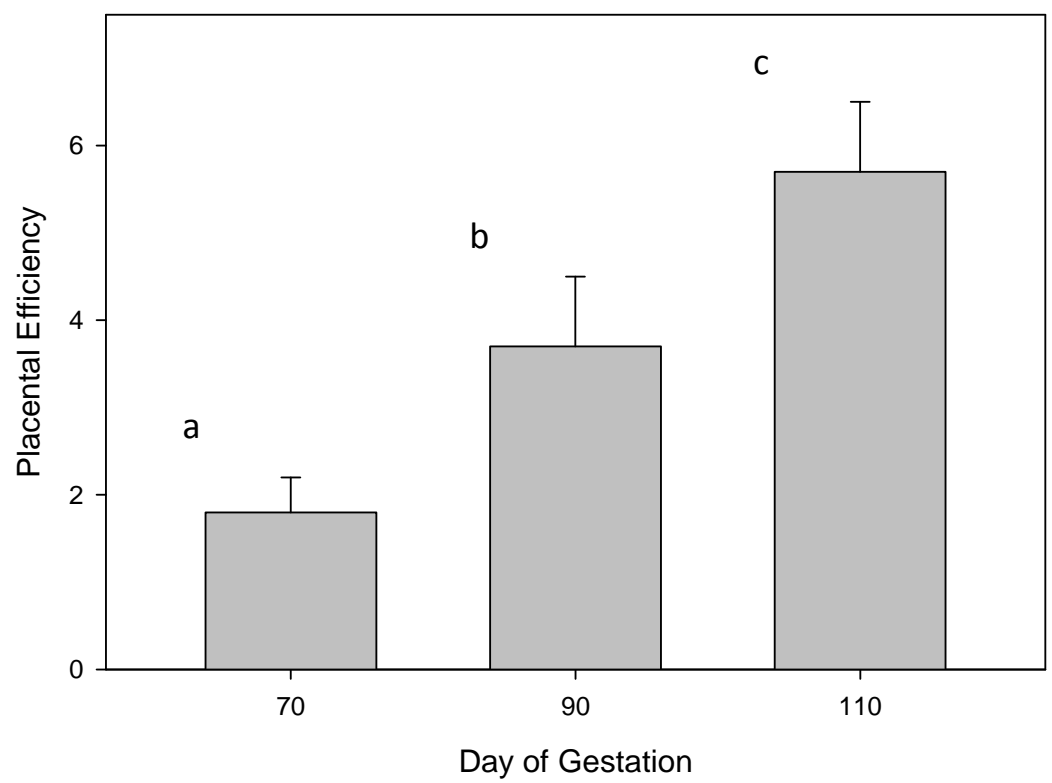

Figure 1: Mean placental efficiency values from litters of pigs on days 70, 90 and 110 of gestation. Different letters indicate a difference $(P<0.0001)$. Mean \pm SEM. 


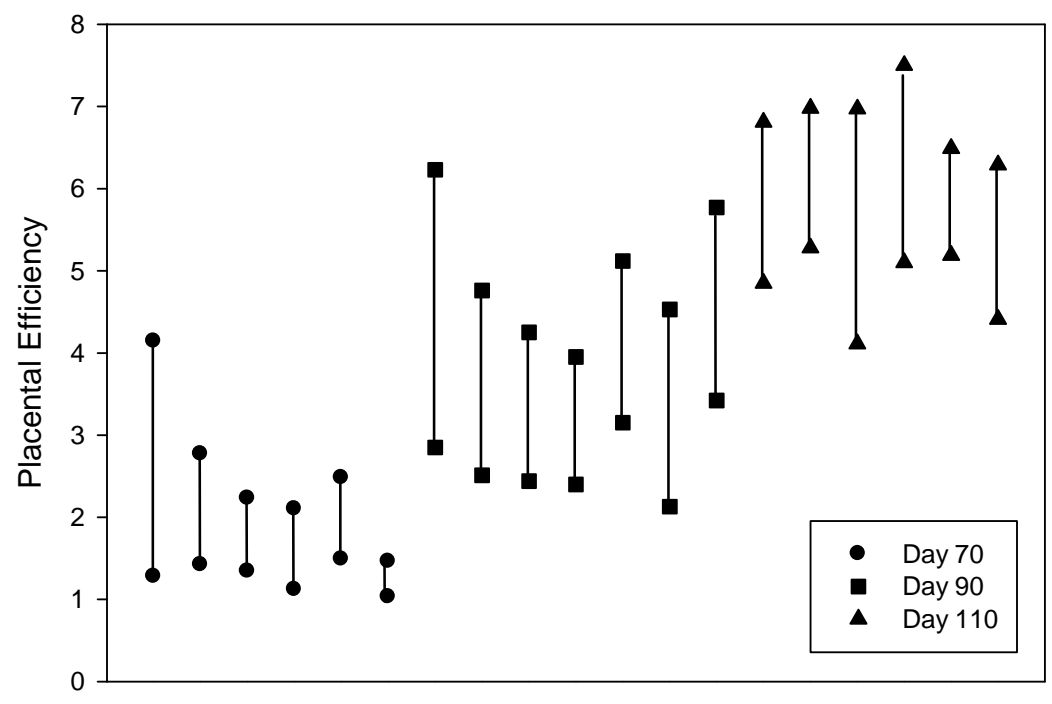

Figure 2: Range of values for placental efficiency for individual litters on day 70, 90 and 110 of gestation. $-\mathbf{D}$ represents litters on day $70, \boldsymbol{D}$ repens litters on day 90 and $\boldsymbol{\Delta}$ represents litters on day 110 
Figure $3 \mathrm{~A}$

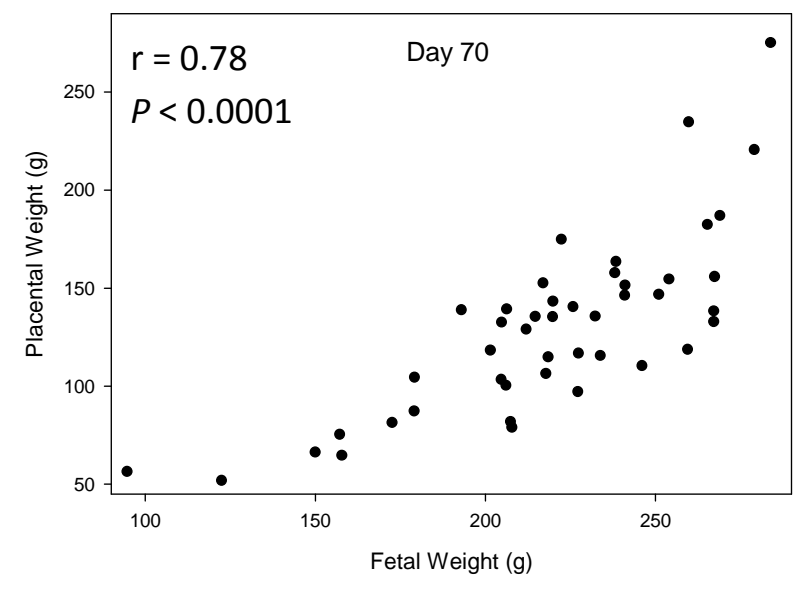

Figure 3B

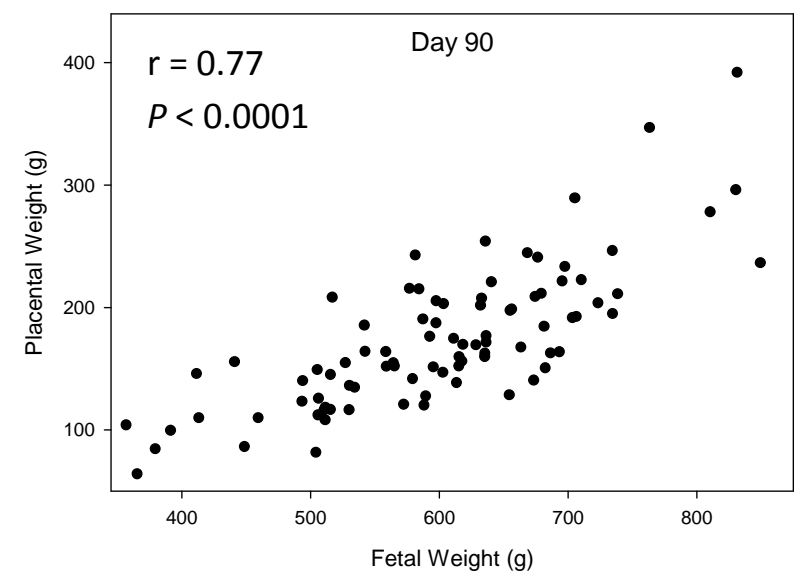

Figure 3C

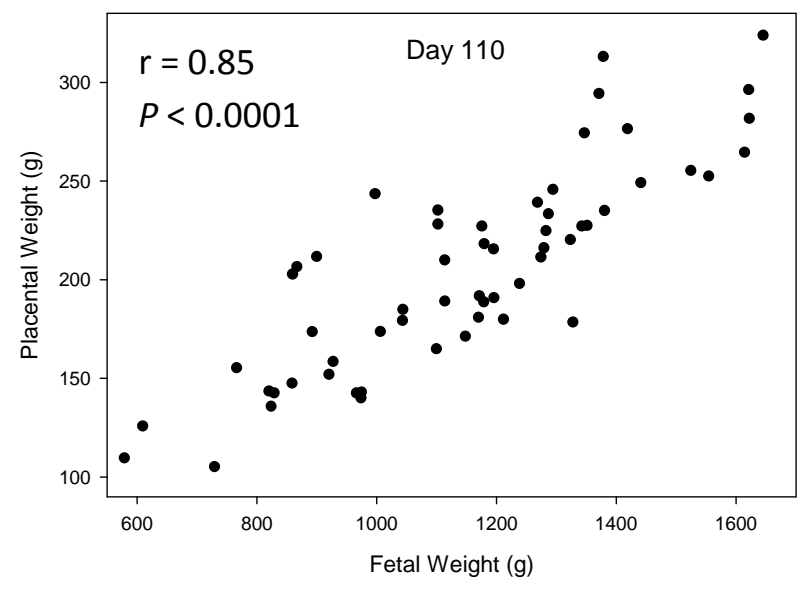

Figure 3: Correlations between placental weight and fetal weight for days 70 (3A), 90 (3B) and 110 (3C) of gestation. Positive relationships were exhibited for each day and were increasingly stronger throughout gestation. 
Figure 4A

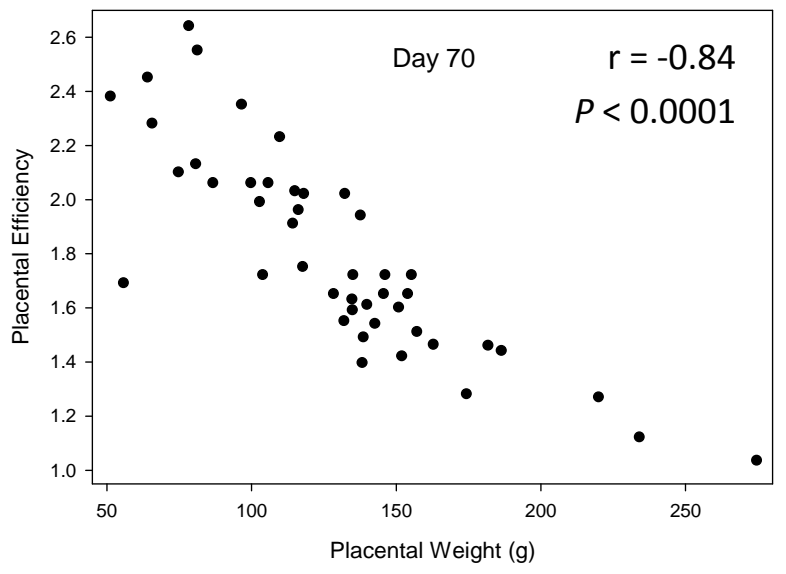

Figure 4B

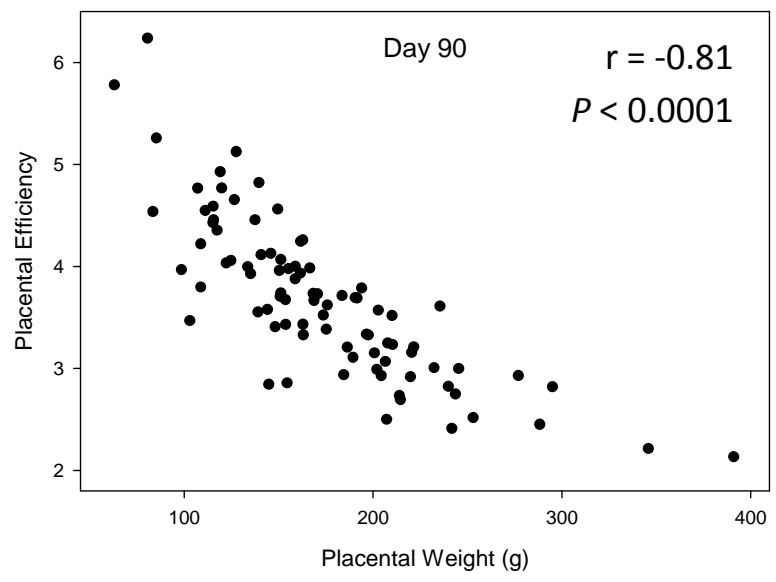

Figure 4C

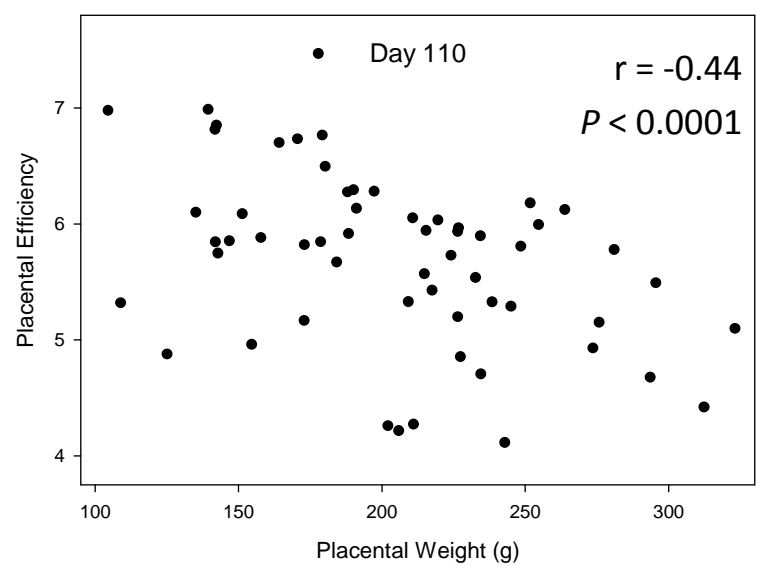

Figure 4: Relationships between placental efficiency and placental weight for days 70 (4A), 90 (4B) and 110 (4C). Negative correlations existed for all days and were reduced as gestation proceeded. 


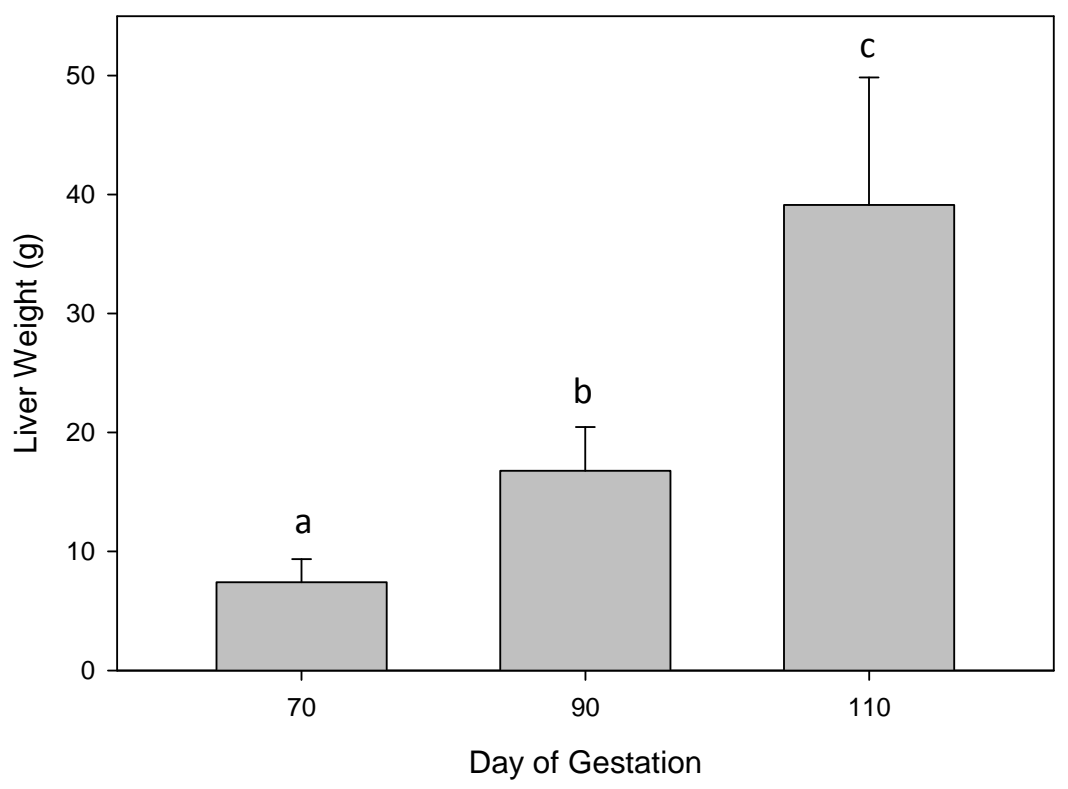

Figure 5: Mean \pm SEM liver weights for litters on day 70, 90 and 110 of gestation. Different letters indicate differences between days of gestation. 


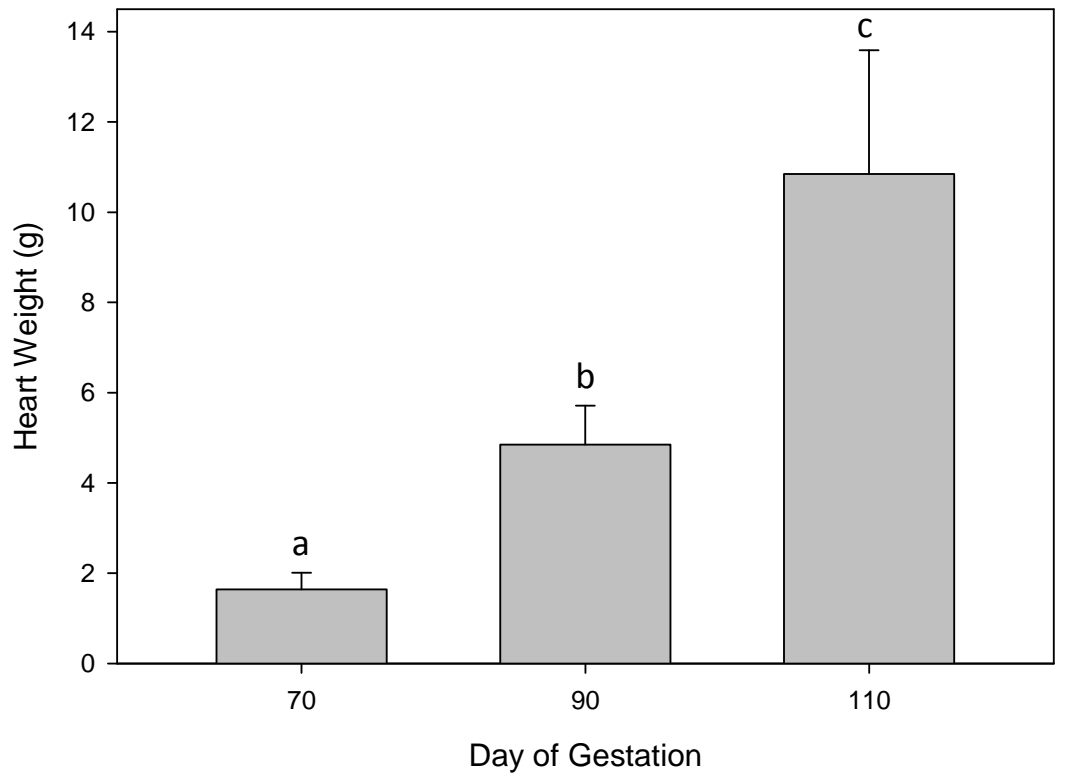

Figure 6: Mean \pm SEM heart weights for litters on days 70, 90 and 110 of gestation. Different letters indicate differences between days of gestation. 


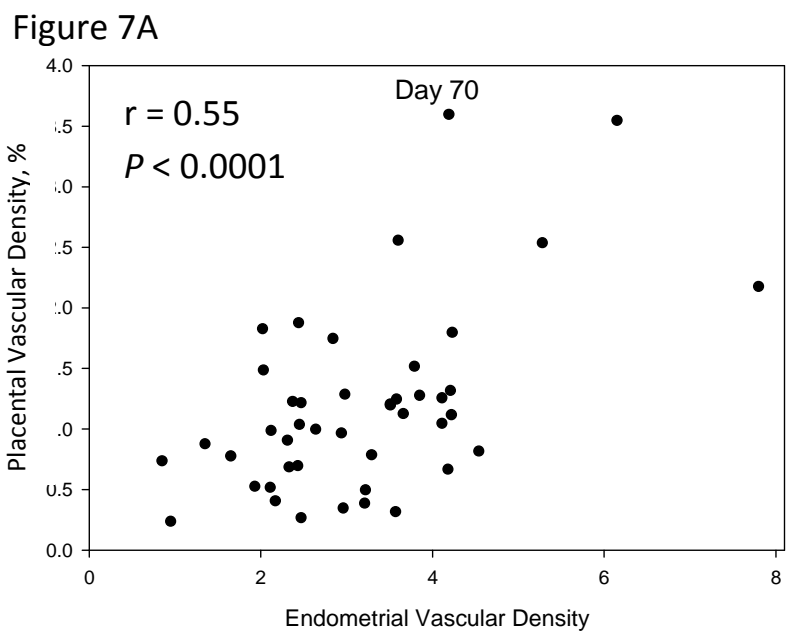

Figure 7B

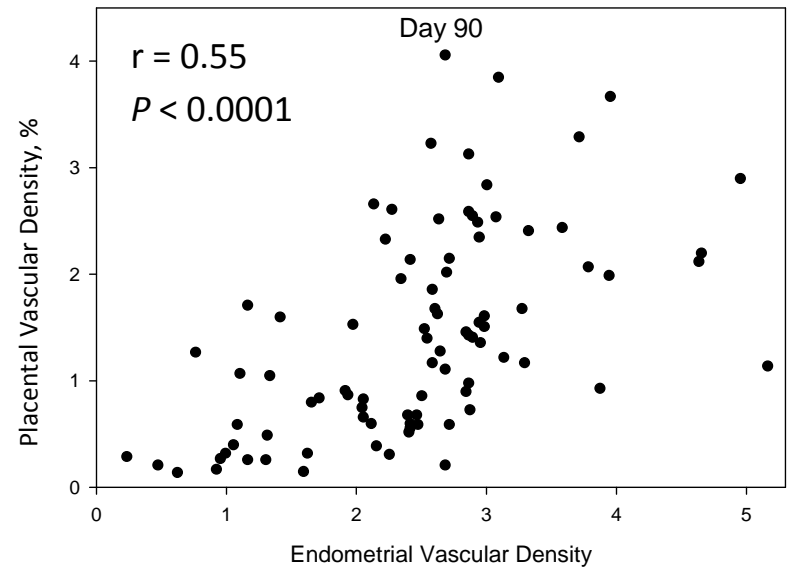

Figure 7C

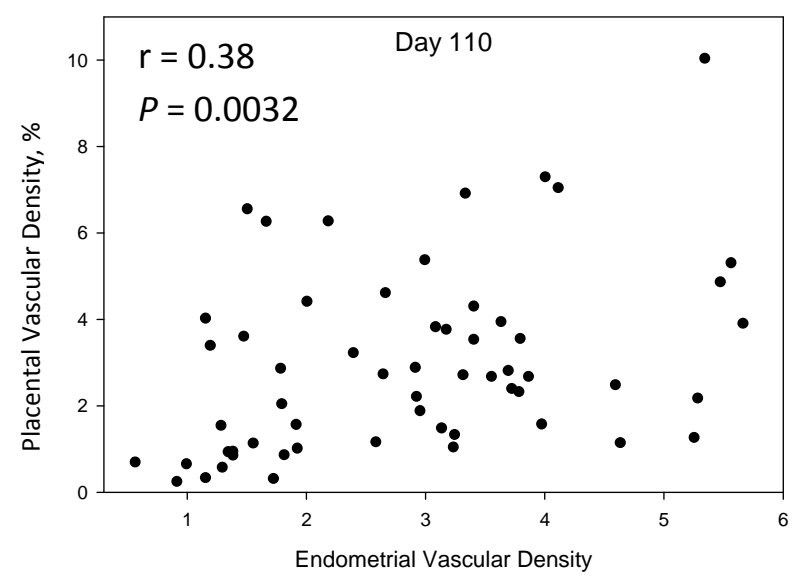

Figure 7: Correlation between placental and endometrial vascular density on day $70(8 \mathrm{~A}), 90(8 \mathrm{~B})$ and $110(8 \mathrm{C})$. Positive correlations were reduced throughout gestation. 


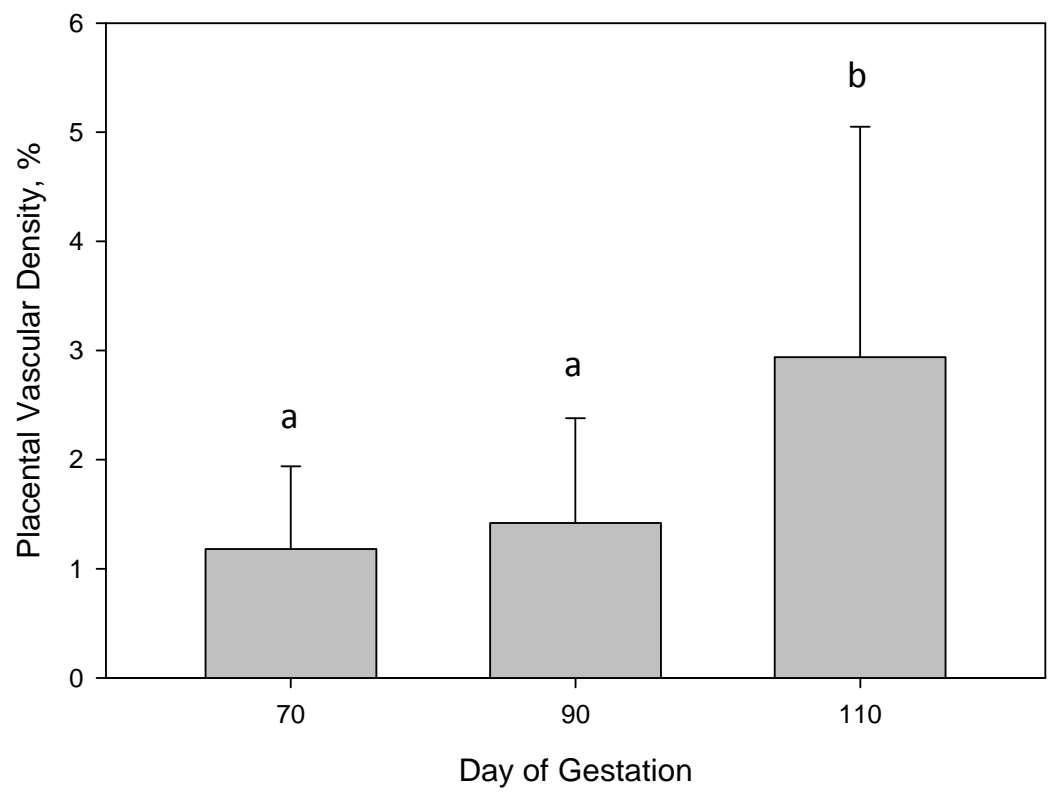

Figure 8: Mean \pm SEM values for placental vascular density on days 70,90 and 110 of gestation. Different letters indicate differences in placental vascular density on day of gestation. 
Figure 9A

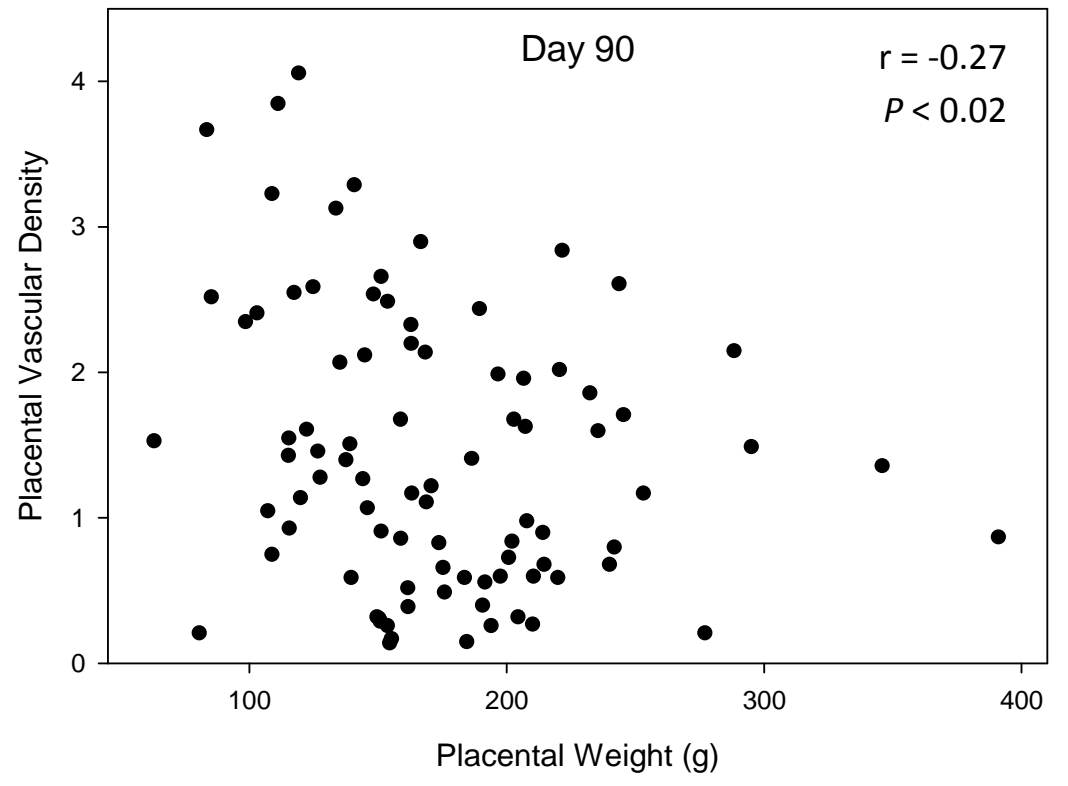

Figure 9B

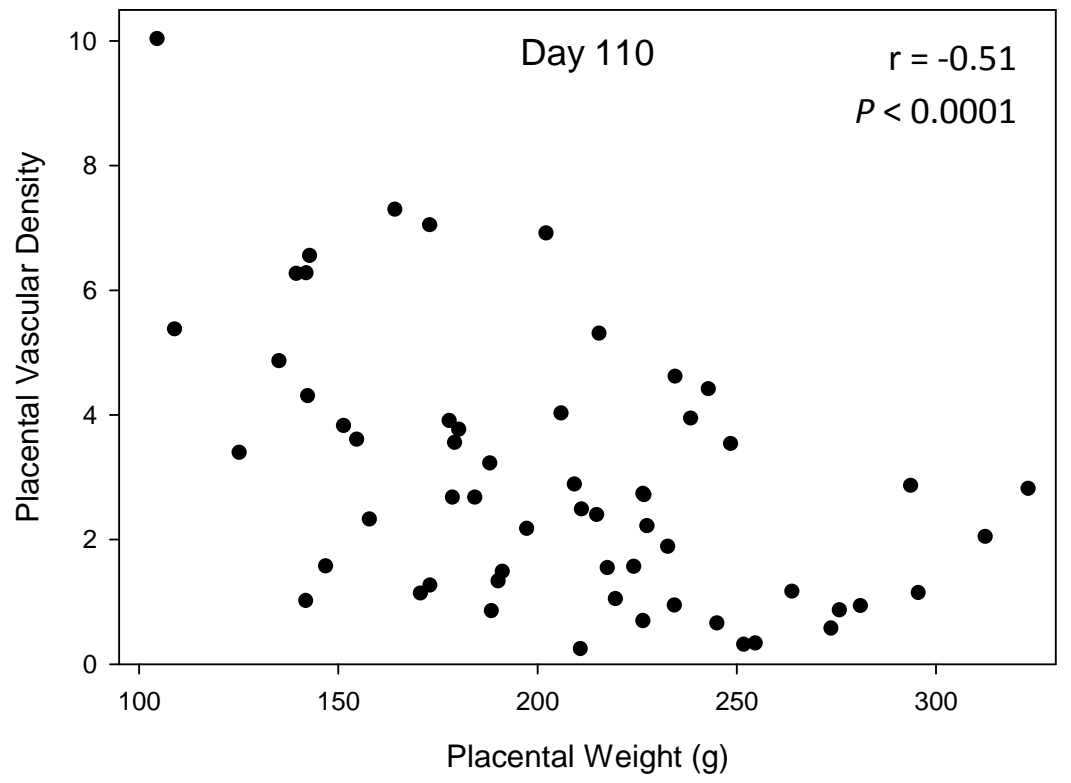

Figure 9: Correlation between placental vascular density and placental weight for days 90 and 110 of gestation. The negative relationship was exhibited by day 90 of gestation. 
Figure 10A

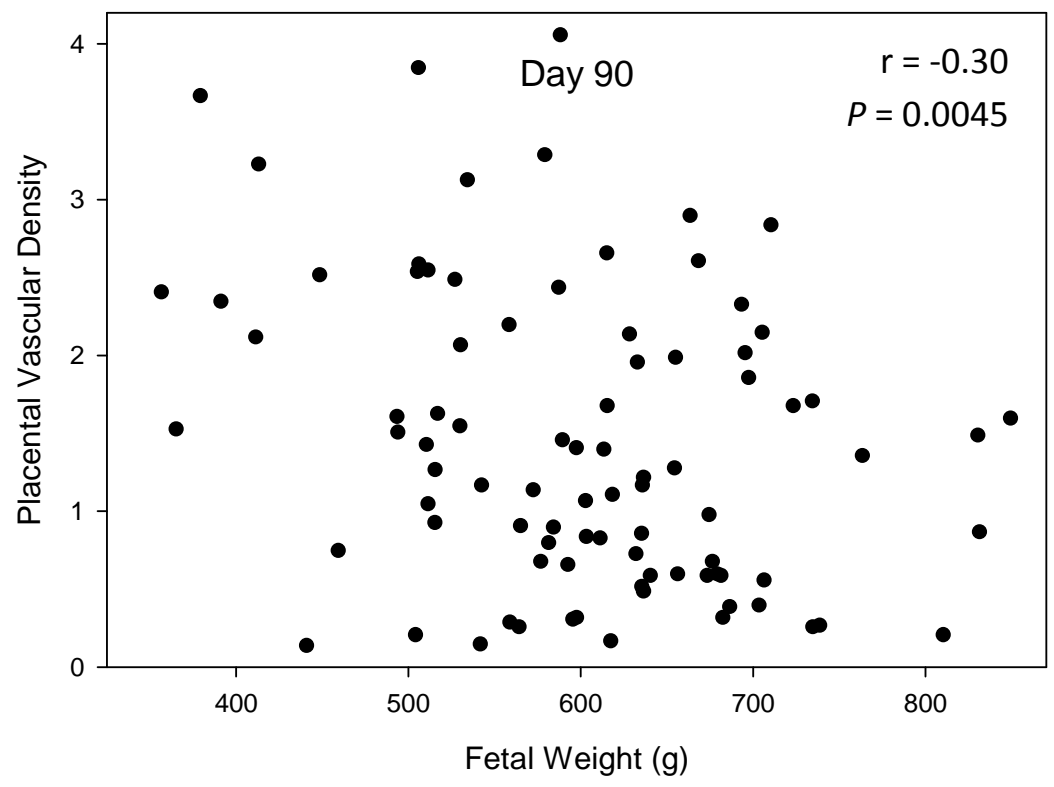

Figure 10B

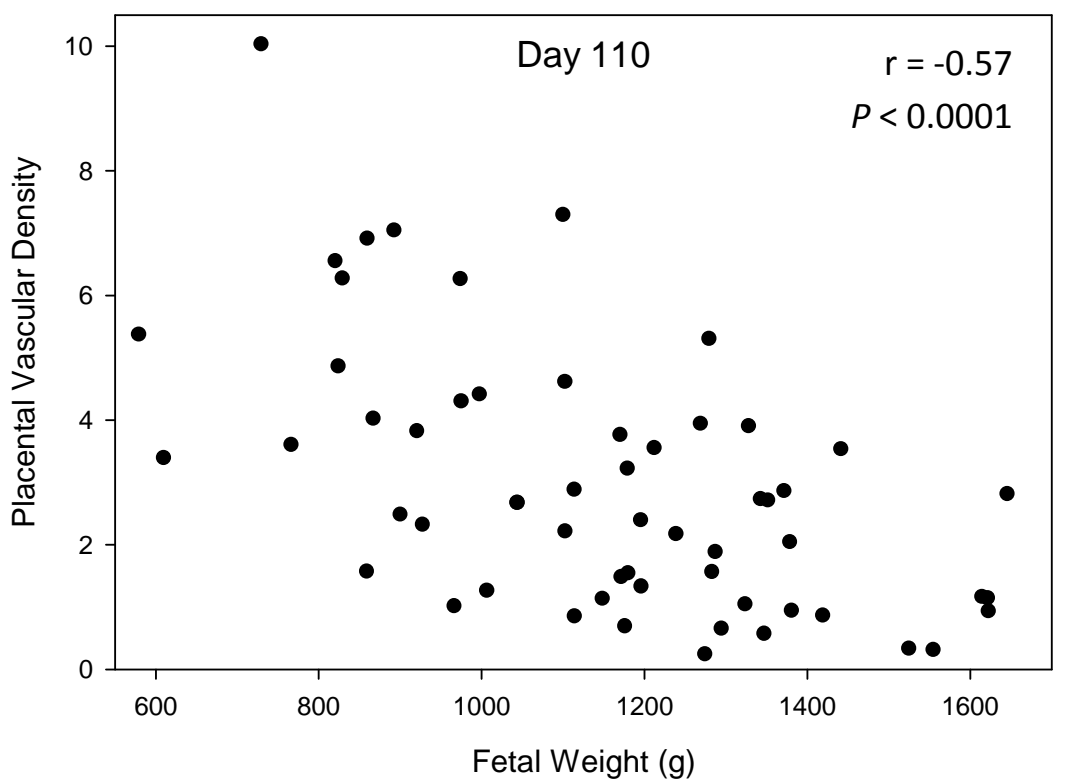

Figure 10: Correlations between placental vascular density and fetal weight for days 90 and 110 of gestation. Relationship was negative and increased from day 90 to day 110. 


\section{Discussion}

The gilts used in this study were from a PIC Camborough line, known for its high number of pigs weaned per litter (PIC, 2008). Camborough lines are also known for their prolificacy and piglet feed efficiency and growth rate. Average litter size of this line is about 14 pigs per litter with average number of weaned pigs being 11.2 (PIC, 2008). Litters produced for this study had an average litter size of 11.1 pigs per litter with an ovulation rate of 15.8 , however the animals used were in their first parities. National average litter size is about 9.5 pigs per litter (NASS, 2009), while average ovulation rate of commercially bred pigs is $22-26$ (Vonnahme et al, 2002).

Placental efficiency increased as gestation proceeded, which is expected because both of its components, fetal and placental weight, are increasing as the placenta grows to meet the needs of the growing fetus. However, fetal weight increases much faster than placental weight and this has been observed before in both Meishan and Yorkshire breeds (Biensen et al., 1998; Wilson et al., 1998). Placental efficiency increased nearly three-fold from day 70 of gestation $(1.8 \pm 0.4)$ to day 110 of gestation (5.7 \pm 0.6 ; Figure 1$)$. We also observed a dramatic increase in the range of placental efficiency from day 70 to day 110 , from 1.03 to 2.64 on day 70 to 4.11 to 7.46 for day 110 , nearly a four-fold increase (Figure 2). This dramatic range in placental efficiency has been observed before by Wilson et al. (1999). It is this variation that we are interested in learning more about.

Placental weight was found to have a positive correlation with fetal weight throughout all observed days of gestation (Figure 3). Knight et al. (1977) also found that fetal weight had relationships with placental characteristics, such as weight and surface area. Placental growth is required to help meet the demanding needs of the growing fetus. The extent to which the placenta can grow is limited, particularly in a crowded uterine environment. Therefore, fetal growth is dependent upon the growth of the placenta, its vascular density and the availability of nutrient transporters in the placenta and adjacent endometrium (Mesa et al., 2003). However, in a larger litter, there will be smaller fetuses and 
placentae, and this will result in a higher placental efficiency. In large litters, a degree of intrauterine crowding will occur, however, intrauterine crowding has more of an impact on placental growth rate than the growth rate of the fetus (Vallet et al., 2003).

Placental efficiency was found to have a very strong inverse relationship with placental weight, though the relationship was reduced by day 110 of gestation (Figure 4). A small placenta will drive the placental efficiency because it is the denominator of the equation. Within a litter, fetuses of similar body weight can have placentae that are vastly different in weight, up to $50 \%$ larger than its similarly sized littermate.

Placental efficiency also shared a relationship with fetal weight (Figure 5). This relationship was small, negative and decreased throughout gestation finally disappearing by day 110 of gestation. In the case of a crowded uterine environment, very small fetuses will be more common and uniformly develop on a very small placenta and the placental efficiency will increase. Larger fetuses will tend to have a less efficient placenta because it is larger to be able to support a larger fetus. It has been shown that increasing litter size through selection for increased placental efficiency resulted in a decrease in fetal body weight (Mesa et al., 2003).

Vascular density was measured in both the placenta and endometrium and was found to exhibit a positive relationship with each other (Figure 8). This relationship is evident at days 70 and 90 of gestation but not for day 110 . Placental vascular density was negatively correlated with placental and fetal weights during the last third of gestation and actually increased from day 90 to 110 (Figures 9 and 10, respectively). The relationship between placental vascular density and placental weight is further supported by the notion that the majority of placental growth is complete by day 90 of gestation. According to Biensen et al. (1999), in Yorkshires (known for their inefficient placentae) in the last third of gestation surface area increased greatly while vascular density remained the same. 
We observed no relationship between vascular density and placental efficiency. Mesa et al. (2003) also found that no relationship existed between placental vascularity and placental efficiency, in either the control group or the group selected for increased litter size. However, Biensen et al. (1998) found that placental vascular density increased in the Meishan (known for high placental efficiency) in the last third of gestation, while vascular density remained the same for Yorkshires. However, we observed a near doubling from day 70 to day 110 in placental vascular density $(1.18 \pm 0.76$ and $2.94 \pm$ 2.11, respecitvely). This difference may be a result of the maternal line used in this study and the straight bred Yorkshires used in the Biensen et al. (1998) study. Biensen et al. (1999) found that both endometrial and placental vascular densities were increased for Meishan conceptuses compared to Yorkshire conceptuses. However, Vonnahme and Ford (2003) selected for increased placental efficiency and found that there was no difference in the diameter of the blood vessels in the placenta and endometrium, but the number of blood vessels per area was greater in animals selected for greater placental efficiency.

The variation that we observed in the range of placental efficiencies, particularly that the range increased from day 70 to day 110 , indicated to us that this variation may be important to further understanding what influences placental function. As a result of our statistical methods, although we found no relationships between placental efficiency and either nutrient transporter mRNA expression or vascular density, we found that both the variation in placental efficiency observed among and within individual litters is significant and must be considered in trying to understand placental efficiency. This variation has been used as a trait for selection (Mesa et al., 2003; 2005).

We also found that day of gestation is an important factor in determining placental efficiency. Placental efficiency increased nearly three-fold from day 70 to day 110 probably due to the rapid growth of both the fetus and placenta at this time. This was also seen by Wilson et al (2000) and Knight et al. (1977). During the last third of gestation the fetus is growing exponentially, however, by this time the 
placenta has stopped growing, though there will be a final bit of growth nearer to term. This rapid increase in fetal growth, in conjunction with a relative lack of placental growth, is the influencing factor in the increase in placental efficiency (Wilson and Ford, 2001).

Our main goal was to see if a relationship existed between the vascular densities and mRNA expression of nutrient transporters in the placenta and endometrium and placental efficiency. We were not able to model placental efficiency with the expression of nutrient transporters we investigated or vascular density in either the placenta or endometrium. Others (Mesa et al., 2003; Vonnahme and Ford, 2003), also did not see a difference in vascular density in animals selected for placental efficiency.

However, Coan et al. (2008) found an increase in the transport of MeAIB in the lightest placenta in litters of mice. We suspect that measuring the RNA message alone for these transporters is not sufficient to determine the influence of transport capacity on placental efficiency.

We also did not observe any interactions between day of gestation and nutrient transporter mRNA expression. Coan et al. (2008) found that transfer of MeAIB, inulin and glucose increased from day 16 to day 19 of gestation, suggesting that measuring the amount of nutrient transported instead of the mRNA of the transporter may be a more efficient method of determining nutrient transport of the placenta.

In conclusion, while nutrient transport and vascular density of the placenta and endometrium may have an influence on placental efficiency, or its variation, we were unable to detect this by measuring the RNA message of nutrient transporters. However, we were able to determine the importance of the within and among litter variation of placental efficiency and that day of gestation has the largest impact on placental efficiency and its variation. 


\section{References}

Bidlingmeyer, B.A., S.A Cohen and T.L. Tarrin. 1984. Rapid analysis of amino acids using precolumn derivatization. J. Chromatog. 336(1):93-104.

Biensen, N.J., M.E. Wilson and S.P. Ford. 1998. The impact of either a Meishan or Yorkshire uterus on Meishan or Yorkshire fetal and placental development to days 70, 90, and 110 of gestation. J. Anim. Sci. 76:2169-2176.

Biensen, N.J., M.E. Wilson and S.P. Ford. 1999. The impacts of uterine environment and fetal genotype on conceptus size and placental vascularity during late gestation in pigs. J. Anim. Sci. 77:954-959.

Christenson, R.K., K.A. Leymaster and L.D. Young. 1987. Justification of unilateral hysterectomyovariectomy as a model to evaluate uterine capacity in swine. J. Anim. Sci. 65:738-744.

Coan, P.M., E. Angiolini, I Sandovici, G.J. Burton, M. Constância and A.L. Fowden. 2008. Adaptations in placental nutrient transfer capacity to meet fetal growth demands depend on placental size in mice. J. Physiol. 586(18):4567-4576.

Costine, B.A., E.K. Inskeep, K.P. Blemings, J.A. Flores and M.E. Wilson. 2007. Mechanisms of reduced luteal sensitivity to prostaglandin F2alpha during maternal recognition of pregnancy in ewes. Domest. Anim. Endocrinol. 32:106-121.

Dziuk, P.J. 1968. Effect of number of embryos and uterine space on embryo survival in the pig. J. Anim. Sci. 27:673-676.

Hajri, T. and N.A. Abumrad. 2002. Fatty acid transport across membranes: Relevance to nutrition and metabolic pathways. Annu. Rev. Nutr. 22:383-415.

Knight, J.W., F.W. Bazer, W.W. Thatcher, D.E. Franke and H.D. Wallace. 1977. Conceptus development in intact and unilaterally hysterectomized-ovariectomized gilts: interrelations among hormonal status, placental development, fetal fluids and fetal growth. J. Anim. Sci. 44:620-637.

Mesa H., T.J. Safranski, R.K. Johnson and W.R. Lamberson. 2003. Correlated response in placental efficiency in swine selected for an index of components of litter size. J. Anim. Sci. 81: 74-79. 
Mesa, H., T.J. Safranski, K.A. Fishcer, K.M. Cammack and W.R. Lamberson. 2005. Selection of placental efficiency in swine: Genetic parameters and trends. J. Anim. Sci. 83:983-991.

Milliken, G.A. and D.E. Johnson. 2002. Analysis of Messy Data, Volume III: Analysis of Covariance. Chapman and Hall/CRC, Boca Raton, FL, USA.

NASS. 2009. March Hogs and Pigs Report. National Agricultureal Statistics Service, USDA, Washington, D.C.

PIC. 2008. Camborough Product Information. Pig Improvement Company, Hendersonville, TN.

Robertson, A.F. and W.B. Karp. 1976. Placental transport of nutrients. Southern Medical Journal 69(10):1358-1362.

Schabenberger, O. 2004. Mixed Model Influence Diagnostics, in Proceedings of the TwentyNinth Annual SAS Users Group International Conference. Paper 189-29, Cary, NC:SAS Institute, USA.

Self, J.T., T.E. Spencer, G.A. Johnson, J. Hu, F.W. Bazer and G. Wu. 2004. Glutamine synthesis in the developing porcine placenta. Biol. Reprod. 70:1444-1451.

Vallet, J.L., H.G. Klemcke, R.K. Christenson and P.L. Pearson. 2003. The effect of breed and intrauterine crowding on fetal erythropoeisis on day 35 of gestation in swine. J. Anim. Sci. 81:2352-2356.

Verbeke, G. and G. Molenberghs. 2000. Linear Mixed Models for Longitudinal Data. SpringerVerlag, Berlin, Germany.

Vonnahme, K.A., M.E. Wilson, G.R. Foxcroft and S.P. Ford. 2002. Impacts of conceptus survival in a commerical swine herd. J. Anim. Sci. 80:553-559.

Vonnahme, K.A. and S.P. Ford. 2003. Placental vascular endothelial growth factor receptor system mRNA expression in pigs selected for placental efficiency. J. Physiol. 554(1):194201.

West, B.T., K.B. Welch and A.T. Galecki. 2007. Linear Mixed Models. Chapman and Hall/CRC, Boca Raton, FL, USA.

Wilson, M.E., N.J. Biensen, C.R. Youngs and S.P. Ford. 1998. Development of Meishan and Yorkshire littermate conceptuses in either a Meishan or Yorkshire uterine environment to day 90 of gestation and to term. Biol. Reprod. 58:905-910. 
Wilson, M.E., N.J. Biensen and S.P. Ford. 1999. Novel insight into the control of litter size in pigs, using placental efficiency as a selection tool. J. Anim. Sci. 77:1654-1658.

Wilson, M.E. and S.P. Ford. 2000. Effect of estradiol-17 $\beta$ during the time of conceptus elongation on placental size at term in Meishan pigs. J. Anim. Sci. 78:1047-1052.

Wilson, M.E. and S.P. Ford. 2001. Comparative aspects of placental efficiency. J. Reprod. Fert. Supp. 53:223-232. 


\section{GENERAL DISCUSSION}

Placental efficiency increases throughout gestation, primarily as a result of the exponential growth of the fetus in the last third of gestation and the relative lack of growth of the placenta during this time. Placental efficiency increased nearly three-fold from day 70 of gestation, when the placenta is still growing, until day 110 of gestation, when the fetus is undergoing rapid growth. The range of placental efficiency increased dramatically throughout gestation as well. On day 70 , placental efficiency ranged from 1.03 to 2.64 but by day 110 , the range was 4.11 to 7.46 , nearly a four-fold increase. Furthermore, littermates of similar body weights are often associated with placentae that are vastly different in size. Some placentae can be as much as $50 \%$ greater than the placenta of its similarly sized littermate. It is this variation that we and others are interested in understanding. Importantly, it is this variation that is crucial to the understanding of placental efficiency altogether.

Placental weight was found to be positively correlated mainly due to the growth of the placenta to try to keep up with the needs of the fetus. Fetal growth is nearly entirely dependent upon the placenta for its nutrient requirement, which is met by transport of nutrients through the placenta. The relationship is negative and is reduced by day 110 of gestation. Selecting for increased litter size has been shown to decrease pig birth weight (Mesa et al, 2003).

Another important factor in the transport of nutrients across the placenta is the amount of vasculature in the placenta and the adjacent endometrium. While we observed a positive correlation between the placental and endometrial vasculature density, we failed to find a relationship of either with placental efficiency. Though others have observed a similar relationship, day of gestation may have been an important factor in the respective data (Biensen et al., 1998), since day of gestation has been shown to have a positive relationship with placental efficiency (Wilson and Ford, 2001). While others looking at this prospective relationship have also been unable to observe it (Mesa et al., 2003). 
We were, however, unable to determine any sort of relationship between placental efficiency and the mRNA expression of nutrient transporters in the placenta and adjacent endometrium. We may simply have been unable to detect this relationship by RNA message, as others have noted an increased transport of certain nutrients in the lightest placenta in litters of mice (Coan et al., 2008). There were also no observed interactions between day of gestation and the expression of these transporters. Coan et al. (2008) measured transport of MeAIB, inulin and glucose increased in the placenta of mice from day 16 to day 19, suggesting that measuring the actual transport of nutrients may be more effective than the measured RNA message of the transporter.

While we were unable to detect any relationships between placental efficiency and nutrient transporters or vascular density, we were able to determine the importance of both within and among litter variation and its potential impact on placental efficiency. 


\section{LITERATURE CITED}

Abumrad, N.A., J.H. Park and C.R. Park. 1984. Permeation of long-chain fatty acid into adipocytes. J. Biol. Chem. 259:8945-8953.

Battaglia, F.C. and G. Meschia. 1988. Fetal nutrition. Ann. Rev. Nutr. 8:43-61.

Bell, A.W., W.W. Hay, Jr and R.A. Ehrhardt. 1999. Placental transport of nutrients and its implications for fetal growth. J.Reprod. Fert. Supp. 54:401-410.

Bidlingmeyer, B.A., S.A Cohen and T.L. Tarrin. 1984. Rapid analysis of amino acids using precolumn derivatization. J. Chromatog. 336(1):93-104.

Biensen, N.J., M.E. Wilson and S.P. Ford. 1998. The impact of either a Meishan or Yorkshire uterus on Meishan or Yorkshire fetal and placental development to days 70, 90, and 110 of gestation. J. Anim. Sci. 76:2169-2176.

Biensen, N.J., M.E. Wilson and S.P. Ford. 1999. The impacts of uterine environment and fetal genotype on conceptus size and placental vascularity during late gestation in pigs. J. Anim. Sci. 77:954-959.

Brocking, A. D. and R. Harding. 2001. Development and function of the placenta. In Fetal Growth and Development, pp. 17-43. [A.D. Brocking and R. Harding, editors]. Cambridge, United Kingdom: Cambridge University Press.

Brossard, N., M. Croset, S. Mormand, J. Pousin, J. Lecerf, M. Laville, J.L. Tayot and M. Largarde. 1997. Human Plasma Albumin Transports [C13] Docosahexaenoic acid in two lipid forms to blood cells. J. Lipid Res. 38:1571-1582.

Cerisuelo, A., M.D. Baucells, J.Gasa, J. Coma, D. Carrión, N. Chapinal and R. Sala. 2009. Increased sow nutrition during midgestation affects muscle fiber development and meat quality, with no consequences on growth performance. J. Anim. Sci. 87:729-739.

Christenson, R.K., K.A. Leymaster and L.D. Young. 1987. Justification of unilateral hysterectomyovariectomy as a model to evaluate uterine capacity in swine. J. Anim. Sci. 65:738-744.

Coan, P.M., E. Angiolini, I Sandovici, G.J. Burton, M. Constância and A.L. Fowden. 2008. Adaptations in placental nutrient transfer capacity to meet fetal growth demands depend on placental size in mice. J. Physiol. 586(18):4567-4576. 
Coburn, C.T., F.F. Knapp, Jr, M. Febbraio, A.L. Beets, R.L. Silverstein and N.A. Abumrad. 2000. Defective uptake and utilization of long chain fatty acids in muscle and adipose tissues of CD36 knockout mice. J. Biol. Chem. 275-32523-32529.

Costine, B.A., E.K. Inskeep, K.P. Blemings, J.A. Flores and M.E. Wilson. 2007. Mechanisms of reduced luteal sensitivity to prostaglandin F2alpha during maternal recognition of pregnancy in ewes. Domest. Anim. Endocrinol. 32:106-121.

Crawford, M.A., W. Doyle, G. Williams and P.J. Drury. 1989. The role of fats and EFAs for energy and cell structures in the growth of fetus and neonate. In The Role of Fats in Human Nutrition, $2^{\text {nd }}$ ed., pp. 81-115 [A.J. Verfroesen and M. Crawford, editors]. London: Academic Press.

Dutta-Roy, A.K., F.M. Campbell, S. Taffesse and M.J. Gordon. 1996. Transport of long-chain polyunsaturated fatty acids across the human placenta: role of fatty acid binding proteins. In $\gamma$-Linolenic Acid: Metabolism and Its Roles in Nutrition and Medicine, pp. 4253. [Y-S Huang and D.E. Mills, editors]. Champaign, IL: AOCS Press.

Dwyer, C.M., A.J.A. Madgwick, A.R. Crook and N.C. Strickland. 1992. The effect of maternal undernutrition on the growth and development of the guinea pig placenta. J. Dev. Phys. 18:295-302.

Dwyer, C.M., J.M. Fletcher and N.C. Strickland. 1993. Muscle cellularity and postnatal frowth in the pig. J. Anim. Sci. 71:3339-3343.

Dyck, G.W. and R.M. McKay. 1986. Intrauterine environmental factors affecting fetal weight at mid-pregnancy in swine. Can. J. Anim. Sci. 66:945-950.

Dziuk, P.J. 1968. Effect of number of embryos and uterine space on embryo survival in the pig. J. Anim. Sci. 27:673-676.

Farnworth, E.R. and J.K.G. Kramer. 1987. Fat metabolism in growing swine: A review. Can. J. Anim. Sci. 67:301-318.

Fenton, F.R., F.L. Schwartz, F.W. Bazer, O.W. Robison and L.C. Ulberg. 1972. Stage of gestation when uterine capacity limits embryo survival in gilts. J. Anim. Sci. 35:383-388.

Finch, A.M., L.G. Yang, M.O. Nwagwu, K.R. Page, H.J. McArdle and C.J. Ashworth. 2004. Placental transport of leucine in a porcine model of low birth weight. Reprod. 128:229235. 
Ford, S.P. and C.R. Youngs. 1993. Early embryonic development in prolific Meishan pigs. J. Reprod. Fert. 48:271-278.

Franck, M., P. Figwer, C. Godfraind, M.T. Poirel, A. Khazzaha, and M.M. Ruchoux. 2007. Could the pale, soft and exudative condition be explained by distinctive histological characteristics? J. Anim. Sci. 85:746-753.

Friess, A.E., F. Sinowatz, R. Skolek-Winnisch and W. Träutner. 1980. The Placenta of the Pig I. Finestructural changes of the placental barrier during pregnancy. Anat. Embryol. 158:179-191.

Friess, A.E., F. Sinowatz, R. Skolek-Winnisch and W. Träutner. 1982. Structure of the epitheliochorial porcine placenta. Biblthca anat. 22:140-143.

Gao, H., G. Wu, T.E. Spencer, G.A. Johnson and F.W. Bazer. 2009. Select nutrients in the ovine uterine lumen. III. Cationic amino acid transporters in the ovine uterus and periimplantation conceptuses. Biol. Reprod. 80: 602-609.

Goodwin, G.W., W. Gibboney, R. Paxton, R.A. Harris and J.A. Lemons. 1987. Activities of branched-chain amino acid aminotransferase and branced-chain 2-oxo acid dehydrogenase complex in tissues of maternal and fetal sheep. Biochem. J. 242:305308.

Hajri, T. and N.A. Abumrad. 2002. Fatty acid transport across membranes: Relevance to nutrition and metabolic pathways. Annu. Rev. Nutr. 22:383-415.

Hay, Jr, William. 1995. Regulation of placental metabolism by glucose supply. Reprod. Fertil. Dev. 7: 365-375.

Hay, Jr, W.W. 2006. Placental-fetal glucose exchange and fetal glucose metabolism. Trans. Am. Clin. Clim. Assoc.117:321-340.

Hegarty, P.V.J. and C.E. Allen. 1978. Effect of pre-natal runting on the post-natal development of skeletal muscle in swine and rats. J. Anim. Sci. 46:620-637.

Holzman, I.R., J.A. Lemons, G. Meschia, F.C. Battaglia. 1977. Ammonia production by the pregnant uterus. Proc. Soc. Exp. Bio. Med. 156:27-30.

Holzman, I.R., A.F. Phillips, F.C. Battaglia. 1979. Glucose metabolism and ammonia production by the human placenta in vitro. Pediatr. Res. 13:117-120. 
Hui, T.Y. and D.A. Bernlohr. 1997. Fatty acid transporters in animal cells. Fron. Bioscience 2:d222-231.

Innis, S.M. 1991. Essential fatty acids in growth and development. Prog. Lip. Res. 30:39-103.

Jaroszewicz, L., M. Jozwik and K. Jaroszewicz. 1971. The activity of aminotransferases in human placental in early pregnancy. Biochem. Med. 5:436-439.

Johnson, L.W. and C.H. Smith. 1980. Monosaccharide transport across microvillous membrane of human placenta. Am. J. Physiol. 250:C637-94.

Karlsson, A.H., R.E. Klont and X. Fernandez. 1999. Skeletal muscle fibres as factors for pork quality. Livest. Prod. Sci. 60:255-269.

Knight, J.W., F.W. Bazer, W.W. Thatcher, D.E. Franke and H.D. Wallace. 1977. Conceptus development in intact and unilaterally hysterectomized-ovariectomized gilts: interrelations among hormonal status, placental development, fetal fluids and fetal growth. J. Anim. Sci. 44:620-637.

Larzul, C., L. Lefaucheur, P. Ecolan, J. Gogue, A. Talmant, P. Sellier. P. Le Roy and G. Monin. 1997. Phenotypic and genetic parameters for longissimus muscle fiber characteristics in relation to growth, carcass, and meat quality traits in Large White pigs. J. Anim. Sci. 75:3126-3137.

Leiser, R. and V. Dantzer. 1988. Structural and functional aspects of porcine placental microvasculature. Anat. and Embryol. 177:409-419.

Leskanich, C.O. and R.C. Noble. 1999. The comparative roles of polyunsaturated fatty acids in pig neonatal development. Brit. J. Nutr. 81:87-106.

Manners, M.J. and M.R. McCrea. 1963. Changes in the chemical compostion of sow-reared piglets during the first month of life. Brit. J. Nutr. 17:495-513.

Marconi, A.M., F.C. Battaglia, G. Meschia and J.W. Sparks. 1989. A comparison of amino acid arteriovenous differences across the liver and placenta of the fetal lamb. Am. J. Physiol. 257 (6 Pt 1): E909-915.

Mateo, R.D., G. Wu, F.W. Bazer, J.C. Park, I. Shinzato and S.W. Kim. 2007. Dietary L-arginine supplementation enhances the reproductive performance of gilts. J. Nutr. 137:652-656. 
Mesa H., T.J. Safranski, R.K. Johnson and W.R. Lamberson. 2003. Correlated response in placental efficiency in swine selected for an index of components of litter size. J. Anim. Sci. 81: 74-79.

Mesa, H., T.J. Safranski, K.A. Fishcer, K.M. Cammack and W.R. Lamberson. 2005. Selection of placental efficiency in swine: Genetic parameters and trends. J. Anim. Sci. 83:983-991.

Monk, E.L. and R.E. Erb. 1974. Effect of unilateral ovariectomy and hysterectomy on reproductive parameters in the gilts during early pregnancy. J. Anim. Sci. 39(2):366-372.

NASS. 2009. March Hogs and Pigs Report. National Agricultureal Statistics Service, USDA, Washington, D.C.

Perry, J.S. 1981. The mammalian fetal membranes. J. Reprod. Fert. 62:321-335.

Ramsey, E.M. and M.W. Donner. 1980. Placental vasculature and circulation. W.B. Saunders Company, Philadelphia.

Ramsay, T. G., J. Karousis, M.E. White and C.K. Wolverton. 1991. Fatty acid metabolism by the porcine placenta. J. Anim. Sci. 69:3645-3654.

Redmer, D.A., J.M. Wallace and L.P. Reynolds. 2004. Effect of nutrient intake during pregnancy on fetal and placental growth and vascular development. Dom. Anim. Endo. 27:199217.

Remesar, X. L. Arola, A Palou, and M. Alemany. 1980. Activities of enzymes involved in aminoacid metabolism in developing rat placenta. Eur. J. Biochem. 110:289-293.

Robertson, A.F. and W.B. Karp. 1976. Placental transport of nutrients. Southern Medical Journal 69(10):1358-1362.

Self, J.T., T.E. Spencer, G.A. Johnson, J. Hu, F.W. Bazer and G. Wu. 2004. Glutamine synthesis in the developing porcine placenta. Biol. Reprod. 70:1444-1451.

Sibley, C., J. Glazier and S. D'Souza. 1997. Placental transport activity and expression in relation to fetal growth. Exp. Phys. 82:389-402.

Smith, C.H. and R. Depper. 1974. Placental amino acid uptake. II. Tissue preincubation, fluid distribution and mechanisms of regulation. Pediat. Res. 8:697-703.

Smith, C.H. and A.J. Moe. 1992. Nutrient transport pathways across the epithelium of the placenta. Annu. Rev. Nutr. 12:183-206. 
Steven, D.H. (Ed.) (1975) Comparative placentation: Essays in structure and function. Academic Press, London.

Thomas, C.R. and C. Lowy. 1987. The interrelationships between circulating maternal esterified and non-esterified fatty acids in pregnant guinea pigs and their relative contributions to the fetal circulation. J. Dev. Phys. 9:203-214.

Thomas, C.R., C. Lowy, R.J. St. Hillaire and J.D. Brunzell. 1984. Studies on the placental hydrolysis and transfer of lipids to the fetal guinea pig. In Fetal Nutrition, Metabolism and Immunology - The Role of the Placenta, pp. 135-146. [R.K. Miller and H.A. Thiede, editors]. New York, NY: Plenum Press.

Town, S.C., C.T. Putnam, N.J. Turchinsky, W.T. Dixon and G.R. Foxcroft. 2004. Number of conceptuses in utero affects porcine fetal muscle development. J. Reprod. Fert. 128:443-454.

Underwood, M.A. and M.P. Sherman. 2006. Nutritional characteristics of amniotic fluid. NewReviews 7:e310-316.

Vonnahme, K.A., M.E. Wilson and S.P. Ford. 2001. Relationship between placental vascular endothelial growth factor expression and placental/endometrial vascularity in the pig. Biol. Reprod. 64:1821-1825.

Vonnahme, K.A., M.E. Wilson, G.R. Foxcroft and S.P. Ford. 2002. Impacts of conceptus survival in a commerical swine herd. J. Anim. Sci. 80:553-559.

Vonnahme, K.A. and S.P. Ford. 2003. Placental vascular endothelial growth factor receptor system mRNA expression in pigs selected for placental efficiency. J. Physiol. 554(1):194201.

Webel, S.K. and P.J. Dziuk. 1974. Effects of stage of gestation and uterine space on prenatal survival in the pig. J. Anim. Sci. 38:960-967.

Wilmoth, T.A., J.M. Koch, D.L. Smith and M.E. Wilson. 2009. Estradiol-17 $\beta$ alters trophectoderm proliferation in pig Embryos. Anim. Reprod. Sci. Submitted.

Wilson, M.E., N.J. Biensen, C.R. Youngs and S.P. Ford. 1998. Development of Meishan and Yorkshire littermate conceptuses in either a Meishan or Yorkshire uterine environment to day 90 of gestation and to term. Biol. Reprod. 58:905-910.

Wilson, M.E., N.J. Biensen and S.P. Ford. 1999. Novel insight into the control of litter size in pigs, using placental efficiency as a selection tool. J. Anim. Sci. 77:1654-1658. 
Wilson, M.E. and S.P. Ford. 2000. Effect of estradiol-17 $\beta$ during the time of conceptus elongation on placental size at term in Meishan pigs. J. Anim. Sci. 78:1047-1052.

Wu, G., F.W. Bazer and W. Tou. 1995. Developmental changes of free amino acid concentrations in fetal fluids of pigs. J. Nutr. 125:2859-2868.

Wu, G., W.G. Pond, T. Ott and F.W. Bazer. 1998. Maternal dietary protein deficiency decreases amnio acids concentrations in fetal plasma and allantoic fluid of pigs. J. Nutr. 128:894902. 